\title{
INDIA: MIGRACIÓN CALIFICADA A LOS PAÍSES DESARROLLADOS Y MIGRACIÓN LABORAL AL GOLFO
}

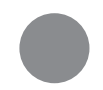

\author{
BINOD KHADRIA
}

TRADUCCIÓN DE LUIS RODOLFO MORÁN QUIROZ

Resumen. Se calcula que en el mundo existen entre 20 y 25 millones de migrantes hindúes que, en conjunto, suelen ser denominados como «diáspora india». Esta cantidad de personas contempla a trabajadores no calificados, escasamente calificados y calificados que han salido de India en los últimos dos siglos. A principios de los años cincuenta, y después de los sesenta como «fuga de cerebros», la migración de personal calificado hacia los países desarrollados del norte se tornó más notable con el reciente éxodo de trabajadores de la tecnología de la información en el siglo XXI. A partir del auge petrolero de los años setenta, grandes cantidades de trabajadores hindúes no calificados y semicalificados han migrado hacia los países del Golfo en el oeste de Asia. El cambio de paradigma en torno a los migrantes calificados que salían de India se dio por etapas, desde la «fuga de cerebros» de los años sesenta y setenta, el «banco de cerebros» de los ochenta y noventa, hasta la "ganancia de cerebros» de principios del siglo xxi. De manera similar, los trabajadores migrantes hacia el Golfo han sido percibidos como la principal fuente de remesas, engrosando las reservas de divisas extranjeras de India. Las dos percepciones requieren ser vistas con cautela.

Palabras clave. Diáspora india, fuga de cerebros, remesas, análisis adversario, educación y salud.

Aвstract. Referred to as «Indian Diaspora», an estimated 20-25 million stock of Indian migrants is recorded world-wide. This is a function of flows of unskilled, semi-skilled and skilled workers from India over last two centuries. Beginning in 1950's, and picking up as «brain drain» in 1960's, skilled migration to developed countries of the North became more prominent with the recent $21^{\text {st }}$-century exodus of the IT workers. Beginning with the oil-boom of the 1970's, large numbers of unskilled and semi-skilled Indian labour have migrated to Gulf countries in west Asia. A paradigm shift about skilled migrants leaving India took place in phases - from the «brain drain» of 1960's-1970's to «brain bank» of 1980's-1990's, and subsequently to «brain gain» in the $21^{\text {st }}$ century. Similarly, the labour migrants to the Gulf have been viewed as the main source of remittances, swelling India's foreign exchange reserves. Both these perceptions need moderation. KEYwORDs. Indian diaspora, brain drain, remittances, adversary analysis, education and health. 


\section{INTRODUCCIÓN:}

\section{UNA VISIÓN GLOBAL DE LA MIGRACIÓN INDIA}

\section{Figure 1}

Percentage Distribution of NRIs and PIOs by Region

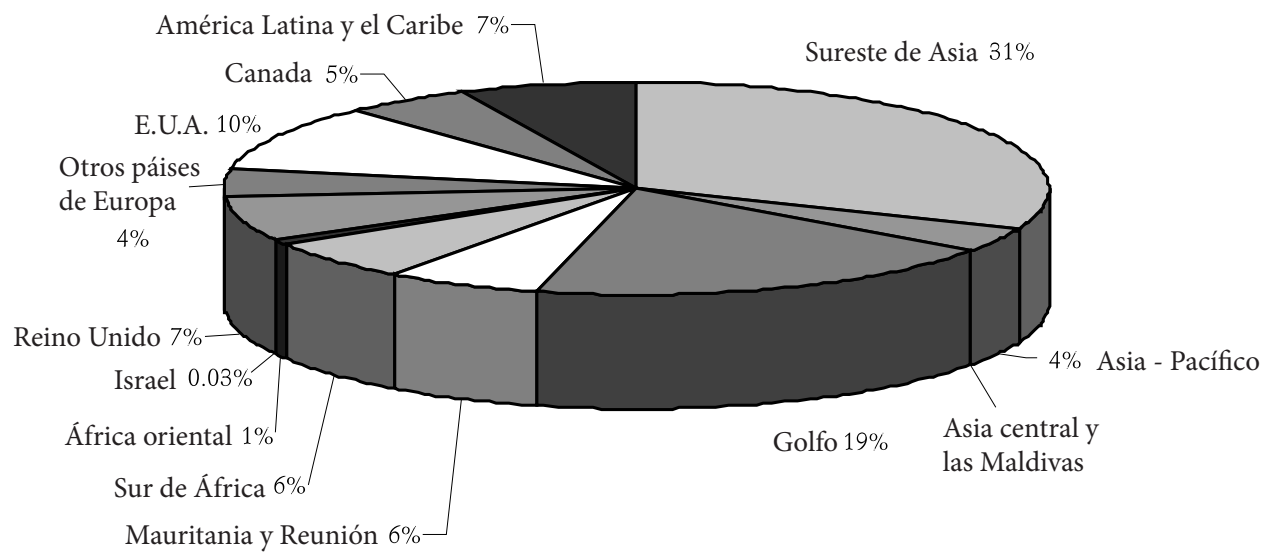

Fuente: ICWA, Report of the High Level Committee on the Indian Diaspora,

Nueva Delhi: Indian Council of World Affairs, 2001.

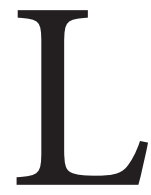

a figura 1 presenta la distribución regional de los destinos registrados a fines del siglo xx, hacia los cuales se dirige una reserva poblacional de cerca de 20 millones de migrantes hindúes — ciudadanos hindúes no residentes (CHNR's), y los extranjeros de origen indio (POH’s) - , a los que suele denominarse «diáspora india» desde que se publicó el informe titulado Report of the High-Level Committee on Indian Diaspora en 2001. ${ }^{1}$ Esta reserva poblacional está compuesta por flujos de trabajadores no calificados, semicalificados y calificados y sus familias provenientes de India, un importante país de origen del sur en los últimos dos siglos. ${ }^{2}$ Es bien sabido que los primeros migrantes que formaron la base para la formación de la llamada diás-

\footnotetext{
${ }^{1}$ Según el cálculo de 1979, realizado por el Ministerio de Asuntos Exteriores de India, acerca del número de personas de origen hindú que residen en el extranjero, la cifra se elevaba a 10.7 millones (Weiner, 1982: 32, citado en Kosinski y Elahi, 1985: 4). Esta cifra es impresionante pero representa apenas el 1.6\% de la población nacional en esa época (el porcentaje se elevó a 2\% en 1999, al llegar a 20 millones de una población de mil millones). No existe una clasificación de tipo cualitativo acerca de los grupos, en la distribución global de la «diáspora india», que supere el nivel de la distribución cuantitativa por país. Estas estimaciones de una sola vez no se complementan con datos del flujo.

${ }^{2}$ India también ha sido un atractivo país de destino para los migrantes provenientes de los países vecinos dentro del subcontinente, tanto para los irregulares como los ilegales, principalmente para los que llegan desde Bangladesh y Nepal así como, en cierto grado, Bután. A veces se menciona también el Tíbet, pero se trata de una región en disputa.
} 
pora india incluían, principalmente, a trabajadores manuales «baratos» que salían de India en cantidades masivas, para responder a la enorme demanda de mano de obra por contrato que surgió en las plantaciones y minas decimonónicas en las colonias, inmediatamente después de que los británicos abolieron la esclavitud en 1834, tanto en el Caribe (Guyana, Jamaica, Trinidad), el Pacífico (Fiji) y el Océano Índico (Mauritania, Sudáfrica y África oriental), y en el sureste de Asia (Malasia, Singapur), así como en los países aledaños del sur de Asia (Sri Lanka y Burma). Esto derivó en lo que se ha dado en llamar «fuga de cerebros». ${ }^{3}$

La «fuga de cerebros», es decir, el éxodo de talento y calificación, la parte superior de los profesionales altamente calificados hacia los países desarrollados, que incluye médicos, ingenieros, científicos, profesores, arquitectos, empresarios y otros, apareció en la India independiente siglo y cuarto más tarde, durante el siglo xx (Khadria, 1999: 62-64). Tras haber comenzado como un goteo en los años cincuenta, la migración de personal calificado hacia los países desarrollados se elevó a mediados de los años sesenta y se hizo más notable con la más reciente migración de trabajadores de la tecnología de la información y de las enfermeras en el siglo xxi, lo que contribuyó inter alia a la concentración de migrantes calificados en Estados Unidos, Canadá, Reino Unido y otros países europeos, además de Australia-Nueva Zelanda. Junto a esta migración de personal calificado hacia los países desarrollados, el siglo xx también ha sido testigo de una migración a gran escala de mano de obra india no calificada y semicalificada hacia los países Golfo en el oeste de Asia, que comenzó en los setentas con la fiebre petrolera, una propensión que todavía continúa.

La emotiva preocupación acerca de que los trabajadores con altos niveles de preparación en las áreas de la tecnología del conocimiento «abandone» India, aunado con la indiferencia ante la masiva migración de mano de obra hacia el Golfo, atravesaron una transformación radical en la percepción pública a principios del siglo xx. Mientras los inmigrantes profesionales han llegado a ser vistos como «ángeles», con una imagen perfeccionada de «ciudadanos hindúes globales» transnacionales capaces de atraer la inversión y la tecnología a India, junto con la idea de que ellos mismos retornan de manera circular al proceso migratorio, la gran cantidad de migrantes con baja calificación, semicalificados o sin calificación alguna, que se dirigen hacia el Golfo, han sido vistos como la principal fuente de remesas que ha desbordado a India con reservas de divisas extranjeras. Estas dos percepciones necesitan matizarse, ya que ello tiene implicaciones positivas y también negativas que deben ser tratadas en conjunto por los países de origen y destino.

\section{LOS ANTECEDENTES CONTEXTUALES EN INDIA}

Los estudios sobre la migración en India han sido muy escasos porque, en términos históricos, la migración jamás ha sido un tema demográfico de importancia debido al

${ }^{3}$ Véase Tinker $(1974,1976,1977)$ para información sobre estas migraciones coloniales procedentes de India. 
pequeño volumen de migración interna en relación con el tamaño de la población total (Bose, 1983: 137). Sin embargo, estas migraciones internas de pequeña escala dentro del subcontinente fueron reemplazadas por una migración masiva hacia el exterior, cuando la división de 1947 creó a India y a Pakistán como dos países distintos. El retiro de los británicos de India y la partición estuvieron asociados con una transferencia masiva de población que se calcula en 14.5 millones, entre los años 1947 y 1951 (Kosinski y Elahi, 1985: 4-5). Inmediatamente después de la partición, cerca de 5 millones de fieles hindis y sikhs salieron de Pakistán hacia India y alrededor de 6 millones de musulmanes se trasladaron a Pakistán desde India (Elahi y Sultana, 1985: 22). Dado que este intercambio, desencadenado por razones políticas, generó problemas serios y de largo plazo en el establecimiento e integración de los refugiados, las perspectivas de la migración proveniente de India dentro del sur de Asia, gradualmente, se vieron más limitadas una vez lograda la independencia. ${ }^{4}$

En contraste, la migración voluntaria, atribuida principalmente a factores económicos y sociales, aunque es más modesta al compararla con la migración relacionada con causas políticas, sigue vigente y parece incrementarse. Los principales flujos han sido los siguientes:

a. Inmigración a Gran Bretaña, un destino que tradicionalmente se prefería en el caso de la migración temporal y que, más tarde, atrajo a personas que se establecieron de manera permanente, pertenecientes a diversos sociales.

b. Los tres países tradicionales para el establecimiento, Australia, Canadá y Estados Unidos, se convirtieron en destinos más atractivos una vez que se modificaron sus políticas migratorias altamente selectivas. Estos países desarrollados, a los que más tarde se unieron Reino Unido y otros países de la Unión Europea, atraerían a trabajadores altamente calificados de India.

c. Un nuevo destino que rápidamente ganó popularidad ha sido el Medio Oriente (Keely, 1980, Ecevit, 1981, Weiner, 1982). Los países ricos en petróleo atraerían, principalmente, la mano de obra semicalificada y no calificada sobre una base temporal circular (Birks y Sinclair, 1980). Algunos países del sureste asiático, como Malasia, también se convertirían, más tarde, en destinos.

\section{MIGRACIÓN CALIFICADA A PAÍSES DESARROLLADOS}

La Segunda Guerra Mundial constituye un parteaguas en la historia de la gestación de

\footnotetext{
${ }^{4}$ Según se evidencia por el retorno patrocinado de antiguos migrantes económicos (provenientes de Sri Lanka hacia India) o refugiados (de Bangladesh en India). Además de los principales flujos relacionados con la división posterior a la guerra, también hubo, empero, algunas migraciones menores relacionadas con acontecimientos políticos en esa área. La creciente presión china, que culminó en invasión e incorporación del Tíbet y la subsiguiente supresión del levantamiento tibetano de 1958-59, derivó en importantes flujos de salida (Elahi y Sultana, 1985: 17-18).
} 
la diáspora india por la emigración hacia el mundo desarrollado (Khadria, 2006c). Era el comienzo de la transformación de la presencia india en los países desarrollado: de ser una presencia minúscula, transitoria y periférica, pasó a una que se tornaría más sustancial, permanente y central. La mayor parte de los migrantes en este periodo se trasladó a Reino Unido, algunos debido a los antiguos lazos coloniales y otros por la experiencia como soldados y marinos en la guerra. Posteriormente, llegarían muchos más tras la partición de India en 1947 que precedería a su independencia. Esta tendencia se fortaleció aún más por los vínculos de parentesco y amistad, principalmente con la región de origen en el estado del Punjab, lo que permitió que otras personas más experimentaran las oportunidades económicas en mercados extranjeros más amplios de mano de obra.

En Canadá, el sentimiento antiasiático caracterizaba a la política de inmigración anterior a la Segunda Guerra Mundial. Sin embargo, durante la posguerra, la cambiante composición de la Commonwealth influyó en el gobierno canadiense. Después de que el primer ministro indio Jawaharlal Nehru visitara Canadá, en 1949, los indocanadienses recibieron el derecho al voto y se cambiaron las previsiones explícitamente racistas de la ley de inmigración.

Hoy en día, en los países desarrollados, el centro de atracción de la migración de mano de obra calificada de origen indio se conserva en Estados Unidos, a donde se traslada hasta el 80\% de la migración india con destino a los países desarrollados. Fue en los años setenta cuando Estados Unidos superó a Reino Unido y Canadá para convertirse en el primer país desarrollado de destino de los hindúes, cuya inmigración hacia Estados Unidos, que no llegaba ni al 1\% de la inmigración global para todos los países en las décadas de los cincuenta y sesenta, superaría el 7\% en 2004 (7.4\% como se muestra en la tabla 1). Todavía en 2003, cuando las preocupaciones por la seguridad en la etapa posterior al 9/11 habían generado un régimen restrictivo hacia la inmigración, la proporción de los hindúes entre los inmigrantes globales continuó creciendo (de $6.7 \%$ en 2002, a $7.1 \%$ en 2003). En las dos categorías más altas de inmigrantes calificados en 2001, es decir, las de ocupados como «profesionales y técnicos» $\mathrm{y}$ «ejecutivos, administrativos y gerenciales», los hindúes ocuparon proporciones tan altas como el $24 \%$ y $11 \%$ del total, respectivamente (como se ve en las cifras de $23.8 \%$ y $11.1 \%$, respectivamente, en la columna c de 2001). En 2003 y 2004, uno de cada cuatro inmigrantes del planeta «con ocupación» ha sido indio (25\% en la columna c para 2003 y $24.7 \%$ en la columna c para 2004$){ }^{5}$

\footnotetext{
${ }^{5}$ Los datos en la columna B, para todos los años, muestran los porcentajes de los inmigrantes hindúes, tomando el número total de inmigrantes hindúes como 100. Los datos en la columna c son los porcentajes de inmigrantes hindúes del total de los inmigrantes admitidos en Estados Unidos provenientes de todos los países del mundo. Sin embargo, dado que no hay clasificaciones por país disponibles para los grupos ocupacionales desde el 2002 (es decir, en el régimen posterior al 9/11) en delante, tampoco hay datos disponibles de las proporciones de los hindúes. Para este periodo, la publicación de las estadísticas de inmigración para Estados Unidos fue retomada por el Departamento de Seguridad Interna - Department of Homeland Security, DHs - de la responsabilidad antes en manos del Servicio de Inmigración y Naturalización -Immigration and Naturalization Service, INs-, quizá debido a la política de limitación de los datos disponibles dadas las crecientes preocupaciones de seguridad.
} 
TABLA 1

Flujo de inmigrantes hindúes ${ }^{*}$ admitidos en Estados Unidos: números absolutos (A), porcentajes (в), y porcentaje de las porciones de entre los inmigrantes globales (с)

\begin{tabular}{|c|c|c|c|}
\hline $\begin{array}{c}\text { AÑOS ANTERIORES } \\
\text { AL } 9 / 11\end{array}$ & $\begin{array}{c}1999 \\
\text { (RÉGIMEN DE DATOS DE INS) }\end{array}$ & $\begin{array}{c}2000 \\
\text { (RÉGIMEN DE DATOS DE INS) }\end{array}$ & $\begin{array}{c}2001 \\
\text { (RÉGIMEN DE DATOS DE INS) }\end{array}$ \\
\hline & A $\quad$ B $\quad$ C & A $\quad$ B $\quad$ C & A $\mathrm{B}$ \\
\hline Todos los inmigrantes & $\begin{array}{lll}30237 & 100.0 & 4.7\end{array}$ & $\begin{array}{lll}42046 & 100.0 & 4.9\end{array}$ & $\begin{array}{lll}70290 & 100.0 & 6.6\end{array}$ \\
\hline Con ocupaciones & $\begin{array}{lll}8016 & 26.5 & 5.7\end{array}$ & $\begin{array}{lll}3724 & 32.7 & 7.2\end{array}$ & $\begin{array}{lll}27073 & 38.5 & 11.3\end{array}$ \\
\hline Ecec/Adm/Geren & $\begin{array}{lll}1112 & 3.7 & 7.1\end{array}$ & $\begin{array}{lll}1644 & 3.9 & 7.9\end{array}$ & $\begin{array}{lll}3062 & 4.3 & 11.1\end{array}$ \\
\hline Profsnl/Tecn & $\begin{array}{lll}3492 & 11.6 & 9.4\end{array}$ & $\begin{array}{lll}8632 & 20.6 & 14.7\end{array}$ & $\begin{array}{lll}19935 & 28.4 & 23.8\end{array}$ \\
\hline $\begin{array}{c}\text { AÑOS POSTERIORES } \\
\text { AL } 9 / 11^{* *}\end{array}$ & $\begin{array}{c}2002 \\
\text { (RÉGIMEN DE DATOS DE DHS) }\end{array}$ & $\begin{array}{c}2003 \\
\text { (RÉGIMEN DE DATOS DE DHS) }\end{array}$ & $\begin{array}{c}2004 \\
\text { (RÉGIMEN DE DATOS DE DHS) }\end{array}$ \\
\hline & A $\quad$ B $\quad$ C & A $\quad$ B $\quad$ C & A $\quad$ B $\quad$ C \\
\hline Todos los inmigrantes & $\begin{array}{lll}71105 & 100.0 & 6.7\end{array}$ & $\begin{array}{lll}50372 & 100.0 & 7.1\end{array}$ & $\begin{array}{lll}70116 & 100.0 & 7.4\end{array}$ \\
\hline Con ocupaciones & $\begin{array}{lll}42885 & 60.3 & 34.5\end{array}$ & $\begin{array}{lll}20560 & 40.8 \quad 25.0\end{array}$ & $\begin{array}{lll}38443 & 54.8 & 24.7\end{array}$ \\
\hline $\begin{array}{c}\text { Ejecutivos/ } \\
\text { Administrativo/ } \\
\text { Gerencial }\end{array}$ & Cifra global: 29277 & Cifra global: 22295 & Cifra global: 31689 \\
\hline Profesional/Técnico & Cifra global: 79370 & Cifra global: 46495 & Cifra global: 73862 \\
\hline
\end{tabular}

Fuente: Autor, utilizando diversos años de los Statistical Yearbooks, del Ins y el DHs de Estados Unidos. Notas: ${ }^{*}$ Por país de nacimiento. ${ }^{* *}$ El desagregado de los datos por países y ocupaciones de los inmigrantes no está disponible en el régimen del DHs.

Las enmiendas de 1965 a la Ley de Inmigración y Nacionalidad de Estados Unidos (us Immigration and Nationality Act), que sería la base de las restantes, se constituyeron como el principal determinante de la inmigración de hindúes altamente calificados hacia Estados Unidos durante los años 1968 a $1992^{6}$ del siglo xx. Dentro del énfasis puesto en el parentesco que se da dentro de las enmiendas de 1965 a la cláusula de reunificación familiar, la nueva legislación establecía, como prioridad, a los profesionales altamente calificados y con un entrenamiento más exhaustivo, al menos así lo hizo de manera explícita para los primeros siete a diez años. Como consecuencia, en Estados Unidos se hicieron claramente visibles las masas de la población indias urbanas, con alta escolaridad y que «hablan inglés», con lo que una buena parte del capital humano de India se trasladó a Estados Unidos, lo que generó una «fuga de cerebros» porque, como registra Jensen (1988: 280), «casi cien mil ingenieros, médicos, científicos, profesores universitarios, maestros de educación básica y sus dependientes habían entrado a

\footnotetext{
${ }^{6}$ Según estas reformas, los inmigrantes estaban sujetos a una «limitación numérica» de 270,000 para todo el mundo y a 20,000 por país al año, lo que se distribuía en un régimen de "preferencia» de seis categorías en el sistema de visado de Estados Unidos, dos bajo el criterio de «necesidades ocupacionales de fuerza de trabajo» de la economía de Estados Unidos y cuatro bajo el «objetivo de reunificación familiar» de la política de población de Estados Unidos.
} 
Estados Unidos para 1975». Sin embargo, desde mediados de la década de los setenta y hasta 1982, la cifra anual de hindúes que entrarían a Estados Unidos se estabilizó en un promedio anual de 20,000 personas, principalmente por la cuota límite establecida por país en la Ley de Inmigración de Estados Unidos. Desde entonces, serían los parientes de los hindúes naturalizados como ciudadanos estadounidenses, exentos de esa cuota, los que incrementarían la cifra de inmigrantes de origen indio, lo que con el tiempo se tornaría en aproximadamente la tercera parte de los inmigrantes. De ese modo, es un hecho que la migración de hindúes altamente calificados hacia Estados Unidos no se redujo; cualquier descenso registrado desde mediados de los setenta era una ilusión estadística y legalista que también, vista en retrospectiva, resultaría temporal. La fuga de cerebros de India hacia Estados Unidos, después de la década de los setenta, se tornaría menos «visible» en lugar de descender realmente.

TABLA 2

Cantidad de ciudadanos hindúes admitidos como trabajadores no-inmigrantes en Estados Unidos, según tipo de visa

\begin{tabular}{|c|c|c|c|c|c|c|}
\hline $\begin{array}{c}\text { PAÍS DE } \\
\text { CIUDADANÍA }\end{array}$ & $\begin{array}{l}\text { ENFERMERAS } \\
\text { REGISTRADAS } \\
(\text { H1A })\end{array}$ & $\begin{array}{c}\text { TRABAJADORES } \\
\text { CON } \\
\text { OCUPACIONES } \\
\text { ESPECIALIZADAS } \\
\text { (H1B) }\end{array}$ & $\begin{array}{c}\text { APRENDICES } \\
\text { INDUSTRIALES } \\
\text { (H3) }\end{array}$ & $\begin{array}{c}\text { VISITANTES DE } \\
\text { INTERCAMBIO } \\
\text { (J1) }\end{array}$ & $\begin{array}{l}\text { TRANSFERENCIAS } \\
\text { DENTRO DE LA } \\
\text { MISMA COMPAÑÍA } \\
\text { (L1) }\end{array}$ & $\begin{array}{c}\text { TRABAJADORES } \\
\text { CON HABILIDADES } \\
\text { EXTRAORDINARIAS } \\
\text { (01) }\end{array}$ \\
\hline India (2001) & 166 & 104,543 & 62 & 5,374 & 15,531 & 666 \\
\hline India (2002) & 228 & 81,091 & 96 & 4,866 & 20,413 & 523 \\
\hline India (2003) & 9 & 75,964 & 136 & 4,732 & 21,748 & 9 \\
\hline
\end{tabular}

Fuente: U.S. DHs, Office of Immigration Statistic, 2003, 2002, 2001 Yearbooks of Immigration Statistics. No hay datos desagregados disponibles para el año 2004 en el reporte anual más reciente (Yearbook 2004).

Después de 1992, sería la vía de la migración temporal, relativamente menos notable, la que comenzaría a predominar. Las enmiendas de 1990, que entraron en vigor en 1992, favorecían, explícitamente, el crecimiento de la cobertura en capital humano de Estados Unidos, llenando sus requerimientos actuales y futuros de trabajadores altamente calificados. Esto hizo que cobrara relevancia la inmigración de hindúes para cubrir las necesidades del mercado laboral estadounidense. Estas enmiendas incluían algunas cláusulas restrictivas, entre ellas, una nueva definición de trabajadores temporales altamente calificados, la bien conocida categoría de visado $\mathrm{H} 1-\mathrm{B}$ para no inmigrantes, con un límite de 65,000 visas por año en todo el mundo, lo que obligó al Senado estadounidense a producir un decreto a fin de lograr la expansión limitada de estas visas a 337,500 para el periodo de tres años entre 1999 y 2001. Esta decisión se explica porque Estados Unidos había enfrentado una caída en el número de graduados de licenciaturas en ciencias, una aguda escasez de personal especializado en las industrias de alta tecnología, como el desarrollo de programas computacionales, y el agotamiento de la cuota anual de visas н1-в para 1998, con 42\% (o casi dos de cada cinco visas) de 
éstas concedidas a profesionales de la programación para la tecnología informática. En 2001, bajó el número de visas H1-B concedidas a los hindúes (Tabla 2) debido a que el escenario de inmigración, en Estados Unidos, se vio más determinado por la agenda de seguridad que resultó del 9/11 y por la posterior recesión que acabó con el entusiasmo por la tecnología de la información, que por las necesidades reales del mercado de mano de obra. Desde entonces, el gobierno de Estados Unidos ha estado bajo constante presión de parte de diferentes grupos de interés, incluidos los de la industria y el comercio estadounidenses, para aumentar nuevamente el límite de las visas H1-B.

FIGURA 2

Distribución de los estudiantes hindúes en el nivel superior en países de recepción afiliados a la OCDE, 2001

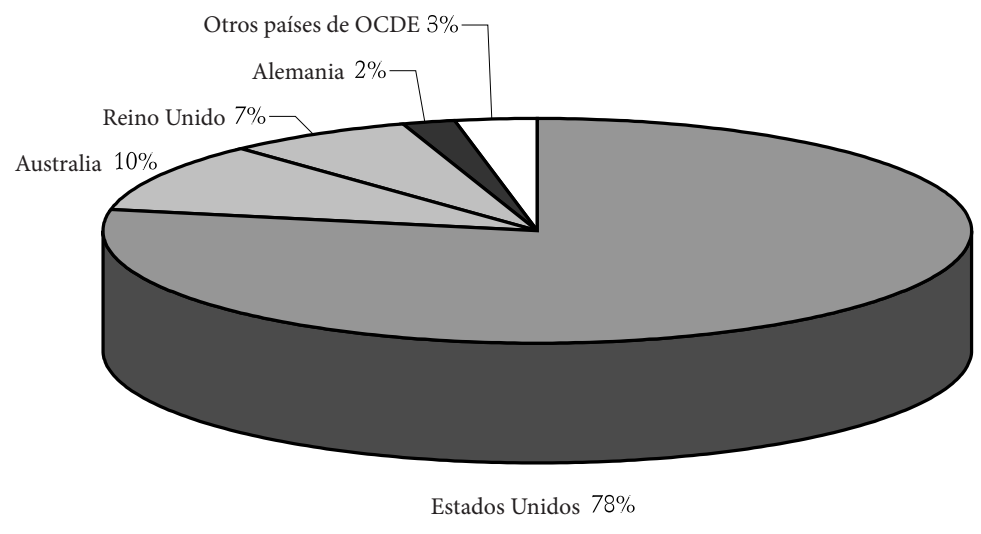

Fuente: Base de datos de la OCDE.

Los hindúes con alta calificación han emigrado a los países desarrollados no sólo por medio de la "puerta del empleo», también ha operado otro flujo de migración de personal calificado a través de la «puerta académica». Esta última se da a medida que las crecientes cohortes de estudiantes comenzaron a formar un conjunto distinto de actores entre los migrantes hindúes, el capital humano «semiterminado» de profesionistas hindúes en el extranjero (Majumdar, 1994; Abella, 2006). Los datos recolectados en el cuestionario realizado por el Us Institute of International Education (Open Doors 2005) revelan que en 2004-2005, India conserva la posición número uno de la matrícula en las universidades de Estados Unidos (seguida por China, Corea, Japón, Canadá y Taiwán) por cuarto año consecutivo. En 2005 y 2006, las cifras de solicitudes de estudiantes hindúes registraron un aumento de $23 \%$ respecto el año anterior, el más alto de todos los países (Hindustan Times, 23 de marzo, 2006). Con el objeto de cumplir el doble propósito de sostener un sistema de educación superior bastante costoso y al tiempo que responde a la escasez de mano de obra en el corto plazo, tanto Reino Unido como Estados Unidos, seguidos por otros países desarrollados, han adoptado la política de permitir, a los estudiantes extranjeros que cursan estudios en sus universidades, la posibilidad 
de quedarse por más tiempo y trabajar en vez de regresar a sus países al graduarse (The Hindustan Times, marzo 2005; Khadria, 2006b). Además, los países de destino obtienen mayores beneficios todavía en lo político: los estudiantes extranjeros se convierten en sus embajadores a largo plazo en el ámbito político internacional. ${ }^{7}$ De tal modo que India se ha convertido en un «destino obligado para las instituciones educativas reconocidas que buscan 'capital de conocimiento' - es decir, para atraer al estudiante indio» (The Hindu, 26 de noviembre de 2000). En octubre de 2000, cuatro países habían establecido «ferias» de educación en Delhi y otras ciudades indias y, desde entonces, se han convertido en un rasgo regular de las relaciones bilaterales en India. La figura 4 muestra que los estudiantes hindúes equivalían al $4 \%$ de todos los estudiantes extranjeros matriculados en la educación terciaria en los países de la oCDE en 2001. En ese mismo año, casi el 80\% de los hindúes que migraban al extranjero en busca de educación superior se trasladaron a Estados Unidos (Figura 2), ocupando así un 10\% de todos los estudiantes extranjeros matriculados en Estados Unidos (Figura 3). En 2004, esta porción de estudiantes hindúes, entre todos los estudiantes extranjeros, alcanzó el 14\%.

\section{FIGURA 3}

Porcentaje de estudiantes hindúes tomando como base a todos los estudiantes extranjeros en los países receptores pertenecientes a la OCDE, 2001

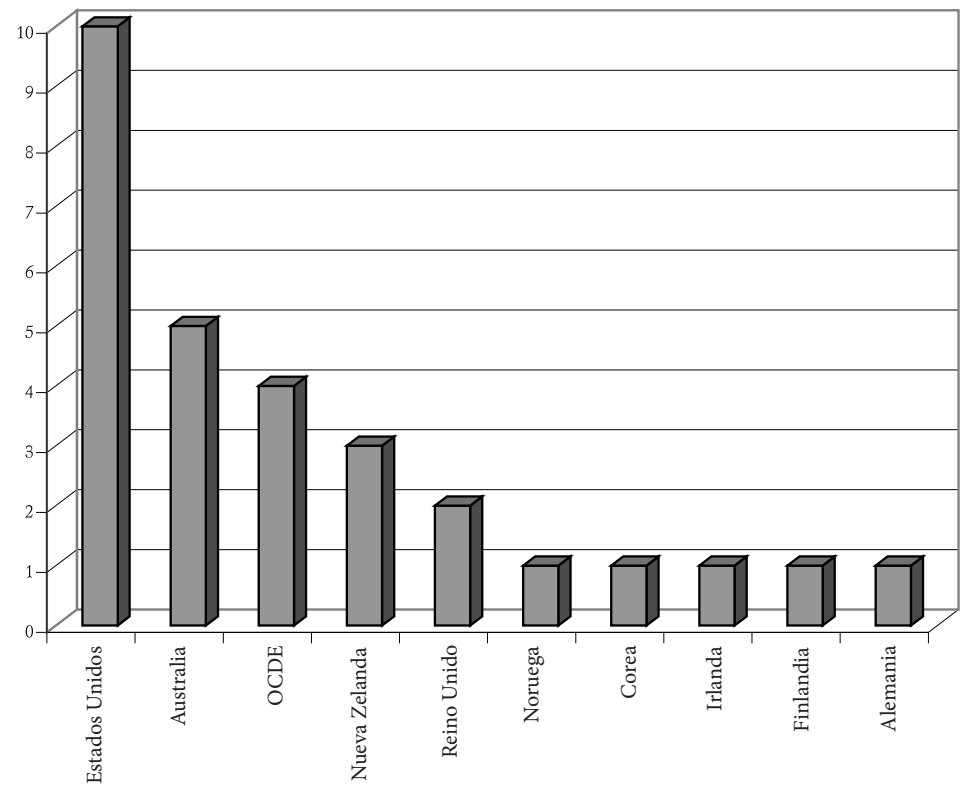

Nota: No se incluyen los datos de Canadá, Grecia, Luxemburgo y Portugal. Fuente: Base de datos de educación de la ocDE.

\footnotetext{
${ }^{7}$ Desempeñan un importante papel en la política mundial como lo hicieron en el pasado, similar al desempeñado por los estudiantes hindúes célebres en Estados Unidos durante la lucha de independencia de India.
} 
La creciente competencia entre países como Estados Unidos, Reino Unido, Canadá, Australia, Nueva Zelanda e Irlanda, además de Singapur y países que no son de habla inglesa, como Francia, Alemania y Holanda, ha motivado a que incluso las instituciones de la Ivy League se sientan atraídas hacia India y también a otros países del sur de Asia en busca de la crema y nata del estudiantado (The Economic Times, 24 de noviembre de 2004).

\section{AUMENTO DEL PODER DE LOS MIGRANTES HINDÚES}

CALIFICADOS EN LOS PAÍSES DESARROLLADOS

El perfil socioeconómico y político de la parte calificada de la diáspora india, que reside en los países desarrollados, refleja el poder que han ganado con el tiempo los migrantes hindúes en los países desarrollados. Dentro de la Unión Europea (UE), la entidad económica de mayor magnitud en el mundo actual, dos terceras partes de la comunidad migrante india todavía residen en Reino Unido. La comunidad india constituye uno de los grupos con más altos ingresos y con mayor escolaridad, lo que les ha permitido lograr preeminencia en los negocios, la tecnología de la información, el sector de la salud, los medios de comunicación, así como en las industrias culinarias y del entretenimiento. En Canadá, con tan sólo el 3\% de una población de 30 millones, los indocanadienses han registrado altos logros en los campos de la medicina, la academia, la administración y la ingeniería. El ingreso promedio anual de los inmigrantes hindúes, en Canadá, es casi $20 \%$ más alto que el promedio nacional y también sus niveles de escolaridad son más altos. En el oriente hay 30,000 ciudadanos hindúes en Australia, mientras que Nueva Zelanda ha sido testigo de un aumento en el ingreso de inmigrantes hindúes profesionistas y de aquellos dedicados a los sectores del comercio doméstico al detalle, la medicina, la hotelería, la tecnología de la información; países como Japón, Corea y Singapur intentan también atraer el talento indio.

En general, el perfil de los inmigrantes hindúes nos permite afirmar que el alto contenido en capital humano, de la migración de los hindúes a Estados Unidos, se ha constituido en la columna vertebral de la formación de una diáspora compuesta por científicos en ese país. Ninguna otra diáspora con un rango numérico mayor a la proveniente de India ha logrado la posición alcanzada por ésta, debido, principalmente, a la demanda estadounidense por las calificaciones laborales de los hindúes, lo que se ha convertido en el principal factor para su admisión a gran escala. Por ello, no es de sorprender que en términos de su lugar en la economía estadounidense, al indexar por empleo, ocupación, escolaridad e ingreso de los inmigrantes, la diáspora india continúe entre los primeros de la lista desde los años setenta hasta la fecha. En Norteamérica existen más de mil organizaciones indias con sede en Estados Unidos, con ramificaciones en Canadá. Estas organizaciones representan a diversos grupos de interés de India y abarcan regiones, estados y lenguas. Las identidades religiosas, de casta, culturales y lingüísticas han encontrado un espacio importante en estas asociaciones y redes. Sin embargo, algunos grupos de profesionales participan en actividades básicas de desarro- 
llo en India, así como en el bienestar de sus miembros profesionistas en el extranjero. Una muestra de las asociaciones puede clasificarse a partir de las principales características de sus miembros o sus funciones, como se muestra en la tabla 3.

TABLA 3

Las asociaciones de la diáspora india en Norteamérica

\begin{tabular}{|c|c|}
\hline CATEGORÍA & ASOCIACIONES \\
\hline $\begin{array}{l}\text { 1. Asociaciones } \\
\text { culturales/religiosas }\end{array}$ & $\begin{array}{l}\text { Samband, Assam Association of North America, Telugu Association of } \\
\text { North America, American Telugu Association (ATA), World Malayali } \\
\text { Council, Bengali Cultural Association, Kenada Koota, Gujarati Samaj, etc. }\end{array}$ \\
\hline $\begin{array}{l}\text { 2. Asociaciones de } \\
\text { estudiantes / ex- alumnos }\end{array}$ & $\begin{array}{l}\text { Mayur en la Universidad Carnegie Mellon; Sangam en el MIT; Ashoka en } \\
\text { la Universidad de California; Diya en la Universidad Duke; sAsA en la } \\
\text { Universidad de Brown; India Club en la Universidad de Boston; Friends of } \\
\text { India, IGSA (Universidad de Houston), y asociaciones de estudiantes hin- } \\
\text { dúes en varias universidades. }\end{array}$ \\
\hline 3. Asociaciones de apoyo & $\begin{array}{l}\text { MITHAs, Manavi, Sakhi, Asian Hindú Women in America (AIWA), Maitri, } \\
\text { Narika, IBAw (Mujeres hindúes de negocios y profesionistas), etc. }\end{array}$ \\
\hline 4. Asociaciones de profesionales & $\begin{array}{l}\text { AAPI, SIPA, NETIP, TIE, EPPIC, SISAB, WIN, AIIMSONIANS, AIPNA, ASEI, IPACA, } \\
\text { IFORI, SABHA, Y IACEF, etc }\end{array}$ \\
\hline 5. Asociaciones de desarrollo & $\begin{array}{l}\text { Association for India's Development (AID), AIA, American India } \\
\text { Foundation }\end{array}$ \\
\hline $\begin{array}{l}6 \text { Asociaciones generales / } \\
\text { redes de amplios alcances }\end{array}$ & $\begin{array}{l}\text { GOPIO, NFIA, The Indian American Forum for Political Education (IAFPE), } \\
\text { The National Association of Americans of Asian Hindú Descent (NAAAID), } \\
\text { y Federation of Indian Associations (FIA), etc. }\end{array}$ \\
\hline
\end{tabular}

Fuentes: Gobierno de la India (Ministry of NRI's Affairs: www.moia.gov.in); portal de la embajada de la India en Estados Unidos; www.garmchai.com; www.nriol.com; www.google.com; www.indiandiaspora.org; www.Indiaday.org.

\section{MIGRACIÓN DE MANO DE \\ OBRA INDIA HACIA EL GOLFO}

Aun cuando los hindúes han cubierto los puestos de oficina y técnicos en las compañías petroleras del Golfo desde que se descubrió petróleo en la región, en los años treinta, todavía es pequeño su número en las cifras totales. Entre 1948 y principios de los años setenta, estas cifras sufrieron un repunte al pasar de 1,400 a 40,000. Cuando comenzaron las actividades de desarrollo a gran escala, después de que se dispararon los precios del petróleo en 1973, en los seis países del Consejo de Cooperación del Golfo (CCG), compuesto por Arabia Saudita, Bahrain, Kuwait, Omán, Qatar y Emiratos Árabes Unidos, comenzó un importante flujo de trabajadores y obreros de India hacia el Golfo. India y Pakistán aportaron la mayor parte de la mano de obra no calificada, que registró un aumento de casi $200 \%$ entre 1970 y 1975. En 1975, los expatriados hindúes constituían el $39.1 \%$, los paquistaníes el $58.1 \%$ y, los provenientes de otros países de Asia, el 2.8\% del total de expatriados provenientes de países no árabes en el Golfo. Desde esa época, la migración india ha superado la que se origina en Pakistán y otros países asiáticos. 
Además, desde la Guerra de Kuwait en 1990-1991, los hindúes han reemplazado en el Golfo incluso a los árabes que no provienen del país, es decir, a los jordanos, yemeníes, palestinos y egipcios. De ser menos de 258,000 en 1975, la población migrante de origen indio en el Golfo se elevó a 3.318 millones en 2001 (Tabla 4), la que se calcula que ha superado los 3.5 millones.

TABLA 4

Población migrante de origen hindú en los países del Golfo, años escogidos entre 1975-2001

\begin{tabular}{|c|c|c|c|c|c|c|}
\hline PAís & 1975 & 1979 & 1983 & 1987 & 1991 & 2001 \\
\hline Arabia Saudita & 34,500 & 100,00 & 270,000 & 380,000 & 600,000 & 1500,000 \\
\hline EAU & 107,500 & 152,000 & 250,000 & 225,000 & 400,00 & 950,000 \\
\hline Omán & 38,5000 & 60,000 & 100,000 & 184,000 & 220,000 & 312,000 \\
\hline Kuwait & 32,105 & 65,000 & 115,000 & 100,000 & 88,000 & 295,000 \\
\hline Qatar & 27,800 & 30,000 & 40,000 & 50,000 & 75,000 & 131,000 \\
\hline Bahrain & 17,250 & 26,000 & 30,000 & 77,000 & 100,000 & 130,000 \\
\hline Total & 257,655 & 433,000 & 805,000 & $1,016,000$ & $1,483,000$ & $3,318,000$ \\
\hline
\end{tabular}

Fuentes: Rahman (1999) y Rajan (2004).

El proceso de admisión a los países del CCG no era tan difícil antes de 1965, pero desde entonces, los países receptores han impuesto restricciones por su temor a que la población extranjera crezca desmesuradamente. Por ende, ha sido difícil que las familias acompañen a los trabajadores extranjeros a sus nuevos destinos, en particular cuando se trata de trabajadores no calificados bajo contrato. Los extranjeros no están autorizados a ser propietarios de negocios o inmuebles en los países del Golfo; para administrar empresas comerciales se les pide que lo hagan sólo como socios de ciudadanos o agencias locales, quienes tendrán una porción mayoritaria en la sociedad, ya sea que se trate de socios activos o «pasivos». En lo que se refiere a los recursos humanos, la escasez de mano de obra ha resultado endémica en todos los países del Golfo, para todos los tipos de puestos, desde profesionistas como médicos y enfermeras, ingenieros, arquitectos, contadores y administradores, pasando por obreros semicalificados como trabajadores manuales, choferes, artesanos y otros trabajadores técnicos, hasta trabajadores no calificados en las construcciones, las granjas, los ranchos ganaderos, talleres, tiendas y hogares.

No obstante, una gran mayoría de los migrantes hindúes en el Golfo, alrededor del 70\%, son trabajadores semicalificados y sin calificación, mientras que el resto está formado por trabajadores de oficina y profesionistas. La tabla 5 presenta su distribución ocupacional hasta el inicio de la Guerra del Golfo en agosto de 1990. El descenso en las cifras para 1991-1992 está directamente relacionado con el control ejercido, por el gobierno de India, sobre los permisos para emigrar en el año que siguió a la guerra del Golfo en 1990-1991, época en que grandes cantidades de hindúes fueron evacuados del Golfo por el gobierno de India. Empero, esta clasificación se recuperó de manera bas- 
tante similar, a pesar de que se dieron algunos cambios para atender la demanda, que se inclina ligeramente hacia los profesionistas calificados, a medida que se desarrolló la infraestructura en el Golfo. En el lado de la oferta, el monitoreo y el control realizados por el gobierno indio de la migración laboral han logrado afinar, hasta cierto grado, el proceso de emigración, sobre todo en los últimos años.

\section{TABLA 5}

Permisos de emigración concedidos por el gobierno de la India hasta antes de la Guerra del Golfo de 1990-1991: mano de obra no calificada y semicalificada por ocupación, 1988-1992

\begin{tabular}{|c|c|c|c|c|c|}
\hline CATEGORÍA & $1987-88$ & $1988-89$ & $1989-90$ & $1990-91$ & 1991-92 \\
\hline Jornalero/Ayudante & 91,196 & 40,657 & 58,779 & 45,028 & 17,345 \\
\hline Ayuda doméstica & 891 & 2,965 & 0 & 1,400 & 1,938 \\
\hline Albañil & 8,550 & 8,731 & 8,913 & 6,323 & 246 \\
\hline Cocinero & 3,550 & 3,051 & 2,070 & 2,386 & 239 \\
\hline Sastre & 5,115 & 4,361 & 3,722 & 3,231 & 163 \\
\hline Vendedor/a & 1,580 & 4,199 & 4,121 & 3,818 & 147 \\
\hline Carpintero & 6,361 & 12,900 & 6,939 & 5,132 & 145 \\
\hline Técnico & 3,539 & 1,450 & 3,389 & 2,642 & 136 \\
\hline Chofer & 6,562 & 6,334 & 6,724 & 5,123 & 131 \\
\hline Electricista & 3,494 & 3,689 & 4,496 & 2,832 & 112 \\
\hline $\begin{array}{l}\text { Mecánico/incluye especialistas } \\
\text { en aire acondicionado. }\end{array}$ & 3,562 & 4,476 & 3,263 & 2,467 & 111 \\
\hline Agricultor & 0 & 0 & & 452 & 108 \\
\hline Pintor & 2,273 & 2,501 & 1,867 & 1,866 & 65 \\
\hline Personal de oficina & 3,916 & 2,211 & 1,385 & 1,087 & 56 \\
\hline Soldador & 1,497 & 1,222 & 3,272 & 1,291 & 55 \\
\hline Operador & 1,309 & 1,855 & 1,342 & 1,001 & 39 \\
\hline Plomero & 1,971 & 1,624 & 2,047 & 1,831 & 33 \\
\hline Capataz & 927 & 906 & 983 & 764 & 30 \\
\hline Ajustador/Fabricante & 1,904 & 2,008 & 2,827 & 1,052 & 29 \\
\hline Supervisor & 1,021 & 813 & 1,069 & 444 & 21 \\
\hline Personal paramédico & 1,349 & 736 & 434 & 437 & 18 \\
\hline Supervisor de ingeniería & 354 & 268 & 248 & 173 & 13 \\
\hline Supervisor & 461 & 264 & 218 & 234 & 12 \\
\hline Acomodador & 0 & 1,690 & 0 & 0 & 0 \\
\hline Otros & 18,284 & 17,778 & 2,565 & 19,302 & 3,074 \\
\hline Total & 169,666 & 126,689 & 120,673 & 110,316 & 24,266 \\
\hline
\end{tabular}

Fuente: Diversos reportes anuales del Ministerio del Trabajo, Gobierno de la India, citados en Rajan (2003). 
La demanda de trabajadores de bajo nivel, como ayudantes domésticos, cocineros, cargadores, jardineros, etc., ha sido grande, aun cuando no es fácil de acceder a datos sistemáticos que cubran a toda India, a excepción del estado de Kerala, en donde desde hace años existe un ministerio exclusivo para atender los asuntos de ese estado en el extranjero. Algunos datos están en proceso de recopilación y ordenación por el recientemente formado Ministerio de la Unión para Asuntos Hindúes en el Extranjero (Union Ministry of Overseas Indians Affairs). Los trabajadores en estas áreas, sin embargo, no gozan de la protección de ley laboral local alguna. Las mujeres que trabajan como empleadas domésticas o institutrices enfrentan malos tratos en algunos países del Golfo y, en ocasiones, incluso son sometidas a abuso sexual (GOI, MOIA, 2006). Los trabajadores no calificados y semicalificados, que trabajan en proyectos de infraestructura y de desarrollo, por lo general viven en condiciones miserables y son ubicados en pequeñas habitaciones congestionadas en los campos de trabajo. Es frecuente que las instalaciones sanitarias y cocinas sean inadecuadas y que las condiciones de trabajo sean pesadas. De ahí que las condiciones de trabajo adversas, los climas desfavorables, la incapacidad de participar en actividades sociales y culturales, junto a largos periodos de separación de las familias y parientes deriven en privación emocional, acabando por arruinar las vidas de los trabajadores hindúes de escasa calificación en el Golfo (Zachariah et al., 2002; GOI, MOIA, 2005-6, 17; GOI, MOIA, 2006).

Los trabajadores no calificados y semicalificados tienen una alta tasa de rotación, ya que sus contratos cubren periodos cortos de empleo y trabajo, por lo general no mayores de dos años cada uno. Quienes terminan su contrato deben regresar a su lugar de origen, aun cuando una alta proporción de ellos logra regresar con un nuevo contrato antes de que se cumpla el año. Esto ha facilitado la proliferación de agencias de reclutamiento y ubicación de personal, algunas veces coludidas con los patrones potenciales para explotar a los aspirantes analfabetas de estos empleos. ${ }^{8}$ Las diversas formas de explotación van desde el retiro de los pasaportes, la negativa a dar el empleo o los salarios prometidos, recortes en los salarios de tiempo extra, deducciones indebidas de las cuotas para permisos de estancia en el salario, transporte inadecuado, instalaciones médicas inadecuadas, negación de los derechos legales para presentar quejas, uso de los migrantes como transporte de bienes de contrabando, victimización y acoso a las mujeres reclutadas para trabajos de ayuda doméstica como sirvientas, cocineras, institutrices, etc. (Overseas Indian, 2006, varios números).

En general, las comunidades de migrantes indias en el Golfo conservan estrechos lazos con su descendencia y parientes en India, lo que incluye frecuentes visitas a sus comunidades de origen. También están al tanto de los acontecimientos políticos y de los cambios socioeconómicos que se dan en India, a través de la prensa, radio y televisión. En épocas de desastres naturales, como los terremotos en India, también han aportado donativos y depósitos en bonos de desarrollo. La mayor parte de las remesas provienen

\footnotetext{
${ }^{8}$ MOIA y el Protectorado de los Emigrantes, del gobierno de India, han comenzado a recolectar las cifras de las quejas recibidas por estos cargos y las acciones que se han dado. Véase GOI, MOIA, 2004-5, 2005-6.
} 
de los trabajadores no calificados cuyos gastos de consumo en el Golfo son mínimos, debido a que sus familias no viven con ellos.

\section{ESTADO DE ORIGEN E IMPLICACIONES SOCIOECONÓMICAS DE}

\section{LA MIGRACIÓN DE MANO DE OBRA: EL CASO KERALA}

La tabla 6 presenta el flujo de salida de mano de obra desde India hacia los seis países del CCG y Jordania en el Golfo en años recientes. ${ }^{9}$ Si no se incluye a Arabia Saudita, Kuwait y Jordania, el resto de los países del Golfo registró un incremento en el flujo de 2005 respecto a 2004. La tabla también facilita la comparación de la migración laboral de India hacia los países del Golfo, frente a los crecientes flujos hacia Malasia en el sureste asiático, país que ha superado al menos a cinco de los siete países del Golfo en años recientes.

TABLA 6

Flujo de salida de trabajadores hindúes hacia el Golfo y otros países, 2000-2005

\begin{tabular}{|c|c|c|c|c|c|c|}
\hline PAÍs DE DESTINO & 2000 & 2001 & 2002 & 2003 & 2004 & 2005 \\
\hline Emiratos Árabes Unidos & 55,099 & 53,673 & 95,034 & 143,804 & 175,262 & 194,412 \\
\hline Arabia Saudita & 58,722 & 78,048 & 99,453 & 121,431 & 123,522 & 99,879 \\
\hline Kuwait & 31,082 & 39,751 & 4,859 & 54,434 & 52,064 & 39,124 \\
\hline Omán & 15,155 & 30,985 & 41,209 & 36,816 & 33,275 & 40,931 \\
\hline Bahrain & 15,909 & 16,382 & 20,807 & 24,778 & 22,980 & 30,060 \\
\hline Qatar & n.a. & 13,829 & 12,596 & 14,251 & 16,325 & 50,222 \\
\hline Jordania & n.a. & n.a. & n.a. & n.a. & 2,576 & 1,851 \\
\hline $\begin{array}{c}\text { Malasia } \\
\text { (Sudeste de Asia) }\end{array}$ & 4,615 & 6,131 & 10,512 & 26,898 & 31,464 & 71,041 \\
\hline $\begin{array}{c}\text { Otros, incl. países del } \\
\text { océano índico }\end{array}$ & 62,600 & 39,865 & 83,193 & 44,044 & 17,492 & 21,333 \\
\hline \begin{tabular}{c} 
Total \\
\hline
\end{tabular} & 243,182 & 278,664 & 367,663 & 466,456 & 474,960 & 548,853 \\
\hline
\end{tabular}

Fuente: obtenido a partir de GOI, MOIA, Annual Reports 2004-5, 2005-6, y

Overseas Indian, vol. 1, núm. 4, abril 2006, p.2, Nueva Delhi.

Estos trabajadores hindúes en el extranjero (overseas Indian workers-oIw's) pro-

\footnotetext{
${ }^{9}$ En India no existe documentación acerca de la migración internacional, ya no se diga de sus diversas subcategorías. Existe una documentación indirecta de la emigración de trabajadores de escasa calificación, en términos de su requerimiento de permisos de salida (ECR: Emigration Clearance Required), en cuanto categoría en sus pasaportes y, de ahí, el número de permisos concedidos por el Protectorado de los Emigrantes del Gobierno de India. Sin embargo, estos cálculos indirectos pueden constituir un estimado exagerado, debido a que no todos salen del país. Por otra parte, estas cifras, por lo general, constituyen un subregistro de la migración real, porque muchas categorías no están cubiertas, por ejemplo, quienes tienen certificados que acreditan más de 12 años de escolaridad; migrantes que permanecen en el extranjero por más de 3 años; personas que pagan sus impuestos de la renta y re-emigran; cónyuges e hijos económicamente dependientes hasta los 24 años de edad en las categorías de ECNR; aquellos que van a países específicos, etc.
} 
vienen principalmente de los tres estados de Kerala, Tamil Nadu y Andhra Pradesh, aunque Karnataka superó a Andhra Pradesh, en 2005, por un amplio margen (Tabla 7). Sin embargo, la mayor parte de ellos proviene de Kerala. Ello ha llevado al establecimiento de un ministerio especial para los oriundos de Kerala que no residen ahí y un aeropuerto internacional en Thiruvananthapuram. Algunos de los otros estados de los que han partido cantidades notables de emigrantes, en calidad de mano de obra hacia el Golfo, son Karnataka, Maharashtra, Punjab y Rajasthan. Los datos de permisos de emigración hacen un registro a la baja de la migración de los trabajadores de Kerala hacia el Golfo, porque una persona que tenga un título universitario está exenta de solicitar permiso para emigrar y la cantidad de graduados universitarios es bastante alta entre los de migrantes de Kerala hacia el Golfo. ${ }^{10}$

TABLA 7

Trabajadores a los que se les concedió permiso de emigración por parte del gobierno de India, por principales estados hindúes, 1993-2005

\begin{tabular}{|c|c|c|c|c|c|c|c|}
\hline ESTADO & 1993 & 1994 & 1995 & 1996 & 1997 & 1998 & 1999 \\
\hline Kerala & 155,208 & 154,407 & 165,629 & 167,325 & 156,102 & 91,720 & 60,445 \\
\hline Tamil Nadu & 70,313 & 70,525 & 65,737 & 64,991 & 63,672 & 69,793 & 47,402 \\
\hline A. Pradesh & 35,578 & 34,508 & 30,284 & 29,995 & 38,278 & 30,599 & 18,983 \\
\hline Maharashtra & 35,248 & 32,178 & 26,312 & 25,214 & 25,146 & 24,657 & 9,871 \\
\hline Karnataka & 34,380 & 32,266 & 33,496 & 33,761 & 40,396 & 11,535 & 5,287 \\
\hline Rajasthan & 25,243 & 27,418 & 28,374 & 18,221 & 28,242 & 19,824 & 9,809 \\
\hline Punjab & 14,212 & 12,445 & 11,852 & 11,751 & 12,414 & 26,876 & 15,167 \\
\hline Otros & 68,156 & 61,638 & 53,650 & 62,956 & 52,174 & 80,160 & 32,588 \\
\hline TOTAL & 438,338 & 425,385 & 415,334 & 414,214 & 416,424 & 355,164 & 199,552 \\
\hline
\end{tabular}

Fuente: Elaborada por el autor. Varios reportes anuales del Ministerio de Trabajo, Gobierno de la India, citados en Rajan (2003, ESCAP) para los datos hasta 1999; GOI, MOIA, Annual Reports 2004-5, 2005-6, para los datos de 2000-05.

En comparación con el resto de India, Kerala aportó un promedio de 25\% de los emigrantes en el siglo xxi, una reducción del 35\% alcanzado en el siglo xx. En otras palabras, uno de cada tres o cuatro hindúes que vive en el Golfo proviene de Kerala. Un estudio anterior de 1998 y 1999 concluye que

la migración constituye el factor más dinámico en un escenario que de otra manera sería paupérrimo en Kerala durante el último cuarto del siglo xx [...] Kerala se acerca

\footnotetext{
${ }^{10}$ Los estados del sur, como Kerala, Tamil Nadu y Bengala occidental, tienen las mayores cifras de graduados en el país. No hay datos en el nivel estatal en cuanto a la exención de permisos de migración, pero, en el nivel de toda India, se ha visto una tendencia creciente en los últimos diez años.
} 
al fin del milenio con pocos motivos para festejar en buena parte de sus hogares, gracias a la migración y al rendimiento económico que trae consigo. En Kerala, la migración debe haber contribuido más a aliviar la pobreza que ningún otro factor, incluidas las reformas agrarias, las actividades sindicales y la legislación para el bienestar social (Zachariah et al., 2000).

Pero otro estudio realizado cinco años después declara, «en las primeras etapas de la emigración desde Kerala, los efectos benéficos superaron a los efectos adversos. Ahora que la emigración de Kerala ha madurado, los efectos secundarios, que no son tan benéficos, comienzan a dejarse ver» (Zachariah et al., 2004). Un importante efecto negativo ha sido el aumento del desempleo debido a la educación y a la «migración de reemplazo» hacia Kerala proveniente de otros estados de India. La emigración ha desempeñado un rol en el incremento de la población con niveles más altos de escolaridad, al disparar la disposición y la capacidad de los jóvenes de Kerala para acceder a mayores niveles educativos. Debido al efecto demostración, una aspiración común es la de «emigrar al Golfo, ganar mucho dinero, casarse y vivir felices para siempre». En años recientes, muchos países del Golfo han tornado obligatorio tener un nivel de escolaridad de educación media para que puedan ingresar los migrantes. Ello ha derivado en un incremento considerable en la demanda de educación en el nivel secundario en Kerala.

Un aspecto importante de la migración de mano de obra india hacia el Golfo ha sido la abrumadora proporción de remesas recibidas, que son enviadas por los trabajadores a India. A mediados de los años setenta se inició un rápido incremento en las remesas ${ }^{11}$ provenientes de los países desarrollados, pero a medida que los emigrantes a estos países fueron seguidos por sus congéneres y familiares, estas remesas fueron sustituidas en proporciones mayores desde el Golfo. La remesas globales hacia India alcanzaron un nivel de 2,083 millones de dólares estadounidenses en 1990-1991, para subir a 8,112 millones en 1994-1995, 11,875 millones en 1997-1998, 12,290 millones en 1999-2000 y, finalmente, 21,700 millones en 2004 (Figura 4). En términos de la proporción del PIB a precios de mercado, ello equivaldría a $0.7 \%$ en $1990-1991$ y a $3.0 \%$ en $1999-2000 .{ }^{12}$

De tal modo, las remesas enviadas por los hindúes expatriados, supuestamente, han contribuido de forma positiva a la economía de India. A mitad de 1991, India enfrentaba una seria crisis en su balanza de pagos. Las reservas de divisas extranjeras se habían desplomado a un nivel que difícilmente cubriría las importaciones básicas por unas cuantas semanas. Los migrantes hindúes en los países desarrollados retiraron sus depósitos en dólares de los bancos hindúes con un ritmo alarmante. Estos problemas requerían de acciones inmediatas para que India estuviera en condiciones de cumplir sus obligaciones internacionales, o ello implicaría el colapso de la economía por falta de importaciones cruciales (Kelegana y Parikh 2003: 111). Serían las remesas provenientes

\footnotetext{
${ }^{11}$ Las remesas se conocen, oficialmente, como Pagos Privados de Transferencias en la cuenta de la balanza de pagos de India.

${ }^{12}$ Reserve Bank of India, Report on Currency and Finance, varios años.
} 
de los trabajadores hindúes en el Golfo, cuyo monto crecía lenta pero constantemente, las que salvarían la situación del país. En la actualidad, India se ubica en el primer lugar de la lista de países receptores de remesas de sus migrantes en el extranjero, casi el 10\% de las remesas mundiales, enviadas por sus 191 millones de migrantes ${ }^{13}$ (figura 4).

\section{FIGURA 4}

Los 20 principales países receptores de divisas, 2004

(en miles de millones de dólares)

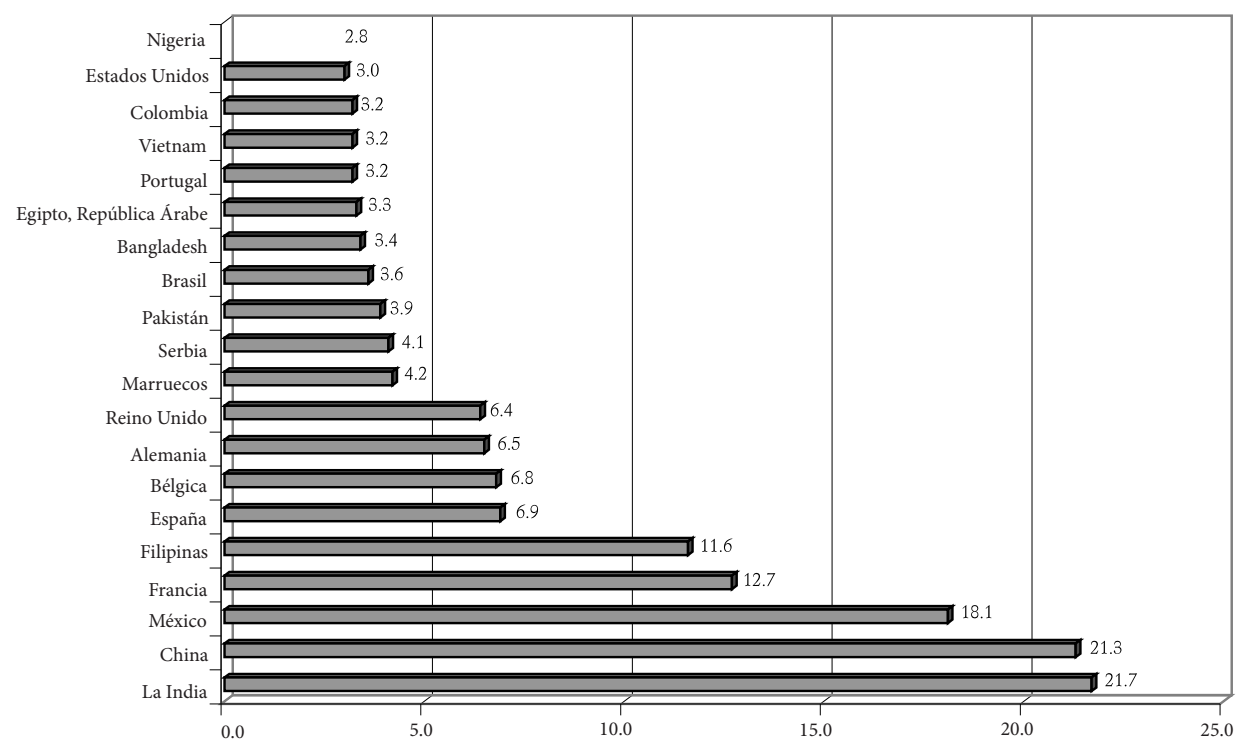

Fuente: Banco Mundial, 2005,

World Economic Outlook, Washington D.c.

La porción correspondiente a Kerala, en la atracción de remesas enviadas por trabajadores hindúes desde el extranjero, no ha sido insignificante. Zachariah et al. (2003: 214-22) han calculado el total de las remesas hacia los hogares de Kerala, según su encuesta de hogares realizada en 1998 en cada uno de los distritos. Según sus estimaciones, el total de las remesas a Kerala alcanzó los Rs. 35,304 millones, cifra que representa un promedio de remesas de Rs. 25,000 por emigrante, y una recepción per cápita de Rs. 1,105 para la población del estado. Como proporción aproximada del PIB del estado de Kerala, esta cantidad se ubica cerca del 10\%. Estas remesas también equivalían a cerca del 10\% de las remesas totales del país, que alcanzaron la cifra de US\$12,000 millones en 1998 con una tasa de cambio de aproximadamente 33 rupias por dólar.

\footnotetext{
${ }^{13}$ Population Headlines, No.310, Marzo-Abril 2005, ESCAP, Bangkok.
} 


\section{LOS DEBATES DE POLÍTICAS Y LOS DISCURSOS PÚBLICOS EN INDIA: PERCEPCIONES CAMBIANTES ACERCA DE LA EMIGRACIÓN DESDE INDIA}

En el momento de su independencia, India contaba con un modesto número de universidades, pero carecía de los recursos humanos altamente calificados en los campos científico y técnico, así como de una base institucional en las áreas de la ciencia y la tecnología (сут) para embarcarse en los planes de industrialización y modernización que se definieron durante las primeras décadas del liderazgo de Nehru. El primer Instituto de Tecnología de India se estableció nueve años después de la independencia, en Kharagpur, en 1956. ${ }^{14}$ Los cinco institutos de tecnología de India (ITI's) se basaron en el modelo del Massachusetts Institute of Technology (МIT) y fueron creados para entrenar a los mejores ingenieros que jugarían un papel importante para asimilar los cambios tecnológicos y revolucionar el programa de industrialización de India. Los ITI’s no sólo generaron espacio para cientos de profesores, sino que también atrajeron a un buen número de ellos que se encontraban en el extranjero. ${ }^{15}$ Dado que todos los ITI's, en un principio, contaban con apoyo intelectual y material de parte de diversos países donantes como Estados Unidos, la Unión de Repúblicas Soviéticas Socialistas (URss), Alemania y Reino Unido, introdujeron sus sistemas de profesores invitados (guest faculty) desde estos países. El intercambio puso a los científicos hindúes en contacto con las fronteras de la investigación tecnológica y la formación avanzada (Indiresan y Nigam, 1993). El Consejo de Investigación Científica e Industrial (Council for Scientific and Industrial Research -CSIR), que instituyó un Registro Nacional de Personal Científico y Técnico a fines de los años cuarenta, creó una sección especial - la de «hindúes en el extranjero» del registro nacional en 1957- orientada a este fin, la que, por supuesto, no tuvo éxito. ${ }^{16}$

La migración de personal altamente calificado de India hacia los países desarrollados fue vista, por primera vez, como fuga de cerebros, cuando el Premio Nóbel de Medicina de 1968 hizo un reconocimiento mundial al dotado científico hindú, Har Gobind Khorana, quien emigrara a Estados Unidos y se naturalizara como ciudadano estadounidense en esa época. Este acontecimiento, sin embargo, significó que los migrantes tuvieran el mote de «desertores de la madre patria India», ya fuera abierta o sutilmente. ${ }^{17}$ De vez en cuando, se concibieron diversas medidas restrictivas para

\footnotetext{
${ }^{14}$ Como secuela de las recomendaciones del comité Sarkar, el Parlamento aprobó el decreto de las ITI en 1956

${ }^{15}$ Científicos prominentes, como Homi Bhabha, S. S. Bhatnagar y D. S. Kothari, realizaron incansables esfuerzos por identificar a los potenciales jóvenes cerebros hindúes, que trabajaban en el extranjero, para persuadirlos de regresar para asumir posiciones de responsabilidad en los laboratorios hindúes. Es bien sabido que Homi Bhabha solía identificar primero un talento y, luego, construir el grupo o subespecialidad en torno a esa personalidad. El Tata Institute of Fundamental Research (TIFR), en Bombay, fue construido de este modo por Bhabha.

${ }^{16}$ Desde 1957, esta sección del registro nacional conserva la base de datos de las personas que cuentan con postgrados en ciencia, ingeniería, medicina, agricultura y ciencias sociales. En un esfuerzo por crear vías para atraer a los científicos y tecnólogos hindúes en el extranjero, el CsIR lanzó, en 1958, un plan denominado «reserva de científicos» (Scientists Pool).

${ }^{17}$ Incluso en términos sociales, cruzar los mares fue visto, durante un tiempo, como un tabú en las comunidades de las castas superiores, como se muestra en las novelas e historias de Munshi Premchand. Fue quizá el efecto
} 
contener el problema, pero nunca ha habido un consenso, más allá del caso del sector médico en donde se introdujeron algunas restricciones, pero con suficientes cláusulas de excepción como para que fueran efectivas.

La característica más notable del periodo es que, todavía, existe una relativa falta de atención pública para definir las políticas para enfrentar el problema de la fuga de cerebros. Los documentos de política educativa de esa época no proporcionaban mecanismo alguno para controlar el problema. La Comisión Kothari (GOI, 1966, sección 198 sobre «Fuga de cerebros») observó que: «No todos los que salen de India son necesariamente científicos de primer rango, ni tampoco tienen una importancia crítica para los requerimientos del país» (Capítulo 16). Gradualmente, el fracaso del programa de industrialización de India, que se proponía absorber el creciente personal altamente calificado proveniente de los institutos de educación, junto con el empequeñecido espacio de empleo en las agencias científicas, llevó a un serio problema de oferta y demanda, contribuyendo a agravarlo todavía más (Blaug et al., 1969).

El discurso político durante este periodo no prestó la atención debida al problema, a pesar de las notables realidades de sobreoferta, desempleo y éxodo de los recursos humanos educados técnicamente hacia el extranjero (Krishna y Khadria, 1997). Como consecuencia, muchos de los inmigrantes hindúes que se trasladaron al Valle del Silicio serían aquellos con una formación de postgrado en Estados Unidos, tras haber emigrado con un título de ingeniería obtenido en los Institutos de Tecnología de la India. Igualmente, muchos médicos con reconocimiento en sus respectivos campos, en Estados Unidos, emigraron con sus primeros títulos recibidos en All India Institute of Medical Sciences (véase tabla 8).

TABLA 8

Fuga de cerebros durante el siglo xx de los graduados de las principales instituciones de ciencias e ingenierías de la India

\begin{tabular}{|c|c|c|c|c|}
\hline INDICADORES & $\begin{array}{c}\text { INDIAN INSTITUTE } \\
\text { OF TECHNOLOGY } \\
\text { BOMBAY, MUMBAI }\end{array}$ & $\begin{array}{c}\text { INDIAN INSTITUTE } \\
\text { OF TECHNOLOGY } \\
\text { MADRAS, CHENNAI }\end{array}$ & $\begin{array}{c}\text { INDIAN INSTITUTE } \\
\text { OF TECHNOLOGY } \\
\text { DELHI, } \\
\text { NUEVA DELHI }\end{array}$ & $\begin{array}{c}\text { ALL INDIA } \\
\text { INSTITUTE OF } \\
\text { MEDICAL SCIENCES, } \\
\text { NUEVA DELHI }\end{array}$ \\
\hline $\begin{array}{c}\text { Cantidad de } \\
\text { graduados }\end{array}$ & $1973-77$ & $1964-87$ & $1980-90$ & $1956-80$ \\
\hline Año de la encuesta & 1987 & 1989 & 1992 & 1997 \\
\hline $\begin{array}{c}\text { Magnitudo de } \\
\text { la fuga de cerebros }\end{array}$ & $31 \%$ & $27 \%$ & $23 \%$ & $56 \%$ \\
\hline
\end{tabular}

Fuente: elaboración del autor, utilizando datos de encuestas realizadas en diversas instituciones, patrocinadas por el Departamento de Ciencia y Tecnología, Gobierno de la India, citado en Khadria (1999).

acumulativo, del nexo entre la diáspora y los aspirantes a migrar, lo que llevó a la disolución de esos tabúes al paso del tiempo, lo que tuvo, como consecuencia, el creciente número de migrantes que se unían a la diáspora hindú en donde fuera que se desarrollara. 
De hecho, fue la Guerra del Golfo, en 1990-1991, la que despertó a los diseñadores de política en India acerca de la vulnerabilidad de sus trabajadores en el Golfo y la importancia de las remesas para la economía. No obstante, dados los cambios en el paradigma de la migración, sería la percepción de la emigración de las personas altamente calificadas, hacia los países desarrollados, la que habría cambiado de forma mucho más dramática que la correspondiente a la migración de mano de obra hacia el Golfo. De tal forma que, a mediados de los años ochenta, la percepción política sobre la «fuga de cerebros» súbitamente había dado lugar a la del «banco de cerebros» en el extranjero, un concepto por el que se inclinaba Rajiv Gandhi cuando asumió el cargo de primer ministro en 1984, tras el asesinato de Indira Gandhi. A lo largo de los años noventa, el éxito cada vez mayor de los migrantes hindúes en Estados Unidos - particularmente la «compra de cuerpos» de los profesionales de la programación cibernética provenientes de Bangalore, el Valle del Silicio de India, así como el trabajo realizado para evitar los efectos de la posible crisis global del $\mathrm{Y} 2 \mathrm{~K}$ - llamaron fuertemente la atención de los países desarrollados de occidente y de oriente (Van der Veer, 2005: 279). El cambio de paradigma, en lo que se refiere a la percepción de los profesionistas migrantes que salían de India, se dio en etapas: desde la «fuga de cerebros» de los años sesenta y setenta, la de «banco de cerebros» de los años ochenta y noventa y la «ganancia de cerebros» del siglo XXI.

A pesar de todo, la burbuja de la tecnología de la información se reventó en el aire al iniciarse la recesión estadounidense y hordas enteras de técnicos tuvieron que regresar a India, tras perder sus contratos con visas H-1B. Los países de la UE, incluido Reino Unido, parecían destinos más estables, mientras que el este y el sureste asiáticos aparecieron como destinos emergentes. Sin embargo, el esquema del canciller alemán, Gerhard Schroeder, según el cual se ofrecerían 20,000 green cards a especialistas en computación de países no afiliados a la UE, principalmente de India (entre 7,000 y $10,000)$ y de Europa oriental, en agosto de 2000, se encontró con protestas callejeras y una oleada de xenofobia con el lema "Kinder stat Inder» (niños, antes que hindúes, $\mathrm{N}$. del т.) que atravesaría toda Alemania. ${ }^{18}$ Eventualmente, las oportunidades de empleo se multiplicaron en India con el surgimiento del proceso de maquila en los sistemas comerciales (business process outsourcing, $\mathrm{BPO}$ ) - las corporaciones multinacionales trasladarían su capital a India, en vez de que la mano de obra saliera del país - desatando una migración de retorno de hindúes, como un apoyo súbito a la economía. ${ }^{19}$

\footnotetext{
${ }^{18} \mathrm{El}$ lema «niños antes que hindúes» («Children instead of Indians») fue acuñado por la oposición política encabezada por el político Juergen Ruettgers, BBC World Service News, "German Right under fire on immigration», jueves 6 de abril, 2000, 20:12 Gмт. Véase también «IT pros may get German green cards», The Hindustan Times, Nueva Delhi, 13 de abril, 2000.

${ }^{19}$ La tendencia a exportar a los profesionistas hindúes de la tecnología de la información o de los programas cibernéticos no es una novedad. Las compañías hindúes se han dedicado a ello durante las ultimas dos décadas: a la práctica de desarrollar programas (software) en Estados Unidos se le llama «compra de cuerpos» («body shopping»), y predominó en los años ochenta y principios de los noventa, principalmente por el hecho de que la historia de desempeño de las compañías de desarrollo de programas en India no había sido evaluada y porque la estructura de telecomunicaciones no estaba plenamente desarrolladas para que, en esa época, fuera posible emplearse en India. A medida que las compañías hindúes comenzaron a hacerse notar en la ejecución de proyectos grandes y complejos, y mejoraron los vínculos de telecomunicación y de satélite, comenzó la tendencia para
} 
De hecho, la más reciente reseña estratégica de nAsscom (NAsscom Strategic Review, 2005a) y el informe NAsscom-McKinsey (2005b) dan cuenta de una gran escasez de personal calificado en especialidades relacionadas con la tecnología de la información (ТI), así como con aquellas vinculadas con el proceso de maquila (вРо) en India. El reporte afirma que, en la actualidad, el $25 \%$ de los técnicos graduados y entre el 10-15\% de los estudiantes de educación superior, en general, estaban capacitados para el empleo en las industrias de ті у вро, respectivamente. Calculaba, además, que para 2010, los dos tipos de industrias tendrían que emplear una fuerza de trabajo adicional cercana a un millón de trabajadores en los alrededores de las ciudades de primer nivel como Nueva Delhi, Bangalore, Hyderabad, Chennai y Mumbai, así como cerca de 600,000 trabajadores en otras áreas de India (Economic Times, 17 de diciembre de 2005). En cuanto a la demanda de talentos, el informe afirmaba que India necesitaría 2.3 millones de trabajadores en las áreas de ті у вро para 2000, con el fin de conservar su actual porción en el mercado. El reporte proyectaba un rezago potencial de casi 500 mil empleados calificados, cerca del 70\% de los cuales se concentraría en la industria вро. De hecho, la industria вро también ha comenzado a atraer extranjeros en busca de empleo hacia India. ${ }^{20}$

Estos repentinos cambios de percepción, que van desde el modelo de formación de una identidad de la diáspora india a través de la migración, hacia el otro —entre la «búsqueda de empleo» por los trabajadores y la «búsqueda de trabajadores» por los patrones - se refleja en la actual respuesta oficial y pública en India, en lo que se refiere a las cambiantes cuotas de inmigración fijadas por los países receptores desarrollados. La postura activa de India hacia su población en el extranjero, que incluye una sustancial diáspora de científicos, refleja únicamente este cambio de paradigma. No sólo es la magnitud de los recorridos económicos, sino también los políticos, lo que los NRI’s (Non-Resident Indians o ciudadanos hindúes residentes en el extranjero) y los PIo's (Persons of Indian Origin o personas cuyos padres o abuelos son de origen indio pero que cambiaron su nacionalidad india por la de su país de residencia, abandonando su nacionalidad original) pueden demostrar a favor de India en sus países de recepción y ello se ha convertido en objeto de orgullo en años recientes, en particular en lo que se

desarrollar programas de software (es decir, en India). Esta tendencia resultó un buen augurio para la industria, elevando en alto grado sus ganancias por exportaciones.

${ }^{20}$ Casi 800 estadounidenses trabajan o realizan su internado en compañías de tecnología de la información en India y se espera que la cifra aumente, según la Asociación nacional de compañías de programación y servicios de India (National Association of Software and Services Companies - NAsscom: Associated Press News, The Economic Times, abril 2, 2006). Los trabajadores provenientes del extranjero también buscan empleos de escasa capacitación, como contestar el teléfono en los centros de llamadas, a cambio de una miseria en comparación con lo que podrían ganar en sus países de origen. Se les ha etiquetado como «trabajadores aventureros»: americanos y europeos que se unen a la fuerza laboral. Aun cuando no hay cálculos exactos de la cantidad de extranjeros que responden las llamadas telefónicas en India, la National Association of Software and Services Companies NASSCOM, la asociación que representa a la industria, ha calculado que hay más de 30,000 expatriados trabajando en la industria de las telecomunicaciones en India y en compañías de trabajo del tipo offshore, tres veces más que la cantidad que había hace tan sólo dos años. La cifra total de personas extranjeras que trabajan en India se calcula en más de 50,000, de las cuales, más de 12,000 están registradas en el centro de la industria de las telecomunicaciones, Bangalore (Asia Times Online, enero 19, 2006, www.atimes.com). 
refiere a liberalización, globalización y competitividad mundial como parte de la agenda de las naciones, ya sean desarrolladas o en desarrollo.

\section{MEDIDAS GUBERNAMENTALES Y PROGRAMAS \\ PARA UNA MEJOR ADMINISTRACIÓN DE LA MIGRACIÓN}

Mientras que las normas para la entrada, regulación y prevención para «extranjeros» en India y las referidas a la ciudadanía india se localizan en la Constitución, el Decreto de Ciudadanía de 1955, el Decreto de pasaportes de 1967, el Código de procedimientos penales y otras regulaciones, no ha existido un marco de política legal sistemático para tratar la emigración del país. A pesar de los debates, discursos y perspectivas, el gobierno de India no tiene una política integral sobre la migración de mano de obra o el empleo en el extranjero, ni en el caso de los trabajadores calificados ni en el de los no calificados. No obstante, el paradigma de la postura de India, en cuanto a esas políticas, podría decirse que se ha modificado con el tiempo, al pasar de un régimen restrictivo a uno compensatorio, luego restaurador y enfocado al desarrollo. ${ }^{21} \mathrm{El}$ decreto de emigración de 1983, que reemplazó el decreto de emigración anterior de 1922, fue diseñado, principalmente, para asegurar la protección de las categorías vulnerables de trabajadores no calificados o semicalificados y de las mujeres que salían al extranjero para trabajar como trabajadoras domésticas. Según ese decreto, es obligatorio que todos los «agentes de reclutamiento» se registren con el ministerio (GOI, MOIA, 2005-6). El papel del gobierno ha sido percibido como el de facilitador en la búsqueda de empleo bien remunerado al máximo número de personas, una preocupación que, nuevamente, se tornó en un tema central desde la independencia de India, dentro y fuera del país.

El recientemente formado Ministerio para los Asuntos de los Hindúes en el Extranjero, constituido en 2004, ha tomado la iniciativa de reformar el decreto de emigración de 1983 y aprobar una serie de medidas relacionadas. Además, existen varios programas que se ubican en el marco de acción de MOIA, incluidos los de evaluación (benchmarking) de las mejores prácticas de otros países de origen con orientaciones progresistas como Filipinas y Sri Lanka (véase GOI, MOIA, 2005-6). Overseas Indian, la publicación del ministerio, ha sido editada en cinco idiomas y también está disponible en versión electrónica. De todas las medidas y programas en India, el denominado «Ciudadanía hindú en el extranjero» (Overseas Citizenship of India-OCI), vinculado con la doble ciudadanía, se ha convertido en una importante marca para redefinir los contornos de la política de migración en el nuevo milenio. Esta medida parece relevante, principalmente para los migrantes altamente calificados que se dirigen a los países desarrollados. Como una segunda medida, se propone que los ciudadanos hindúes en el extranjero tengan el derecho a votar desde fuera de India, dirigida principalmente a los obreros en el Golfo, quienes envían grandes cantidades de remesas a su país de origen, pero que no pueden

\footnotetext{
${ }^{21}$ Una elaboración de estos regímenes se encuentra en Khadria (2002).
} 
esperar convertirse en ciudadanos naturalizados de esos países por los restrictivos regímenes existentes en los países de destino. Sin embargo, todavía es muy pronto para medir el impacto de estas dos medidas, ya que ambas están en sus inicios.

\title{
CONCLUSIÓN: UNA VALORACIÓN CRÍTICA DEL IMPACTO SOCIOECONÓMICO EN INDIA
}

\begin{abstract}
¿De qué modo podría evaluarse si la migración ha cambiado a la sociedad hindú y si ha contribuido de manera adecuada al desarrollo social y económico de India? En otras palabras, ¿cuáles han sido las ganancias y las pérdidas socioeconómicas derivadas de la migración? Estas preguntas se han planteado tradicionalmente al sugerir un análisis de costo-beneficio en el nivel micro, que incluye al migrante individual y su hogar, así
\end{abstract} como en el nivel macro, es decir, la sociedad y la economía en general.

Aun cuando se asuma que la evaluación a nivel micro de los beneficios y pérdidas para las familias que se quedan en India puede identificarlos y medirlos adecuadamente, no existen muchas encuestas que expliquen, apropiadamente, las pérdidas psicológicas que implica la separación de los miembros de la familia, a excepción de los pocos estudios realizados en el estado de Kerala. Por ejemplo, la emigración de los hombres casados, que dejan la responsabilidad de la administración del hogar a las mujeres, transformó a cerca de un millón de mujeres en eficientes administradoras del hogar. A largo plazo creó problemas sociales y psicológicos de las «esposas del Golfo» aunado a la soledad de los «padres del Golfo», trabajadores que, a diferencia de los parientes de los migrantes calificados que parten a los países desarrollados, no acompañaron a los trabajadores hacia sus países de destino (Zachariah et al., 2003: 329-39; Zachariah y Rajan, 2004: 48). El incremento en la migración temporal, en comparación con la migración permanente, incluso entre los migrantes calificados hacia los países desarrollados, también ha generado lo que en otro lugar he llamado las «familias nómadas» $y$ una nueva forma de «regreso forzado» en el caso de los migrantes calificados, pero ello no ha sido evaluado ni analizado (Khadria, 2006a). ${ }^{22}$

Otra faceta relacionada, pero no atendida de la migración india, ha sido la referida al tema del género. No hay datos globales disponibles acerca de las mujeres migrantes, como dependientes o como trabajadoras, que permitan realizar un análisis a profundidad de las tendencias que siguen y de los impactos que tienen. Existen algunos datos de los países receptores, como el censo de Estados Unidos o los de la fuerza laboral de Reino Unido, que indican la proporción de mujeres entre la población de origen hindú que incluye a los migrantes o a grupos particulares de profesionales, como las enfermeras, así como algunos datos sobre las sirvientas indias en Singapur. Más allá de eso, los

\footnotetext{
${ }^{22} \mathrm{El}$ asunto normal de la migración forzada, en términos de hindúes que solicitan status de refugiados en Europa, Estados Unidos o algún otro lugar, no ha llamado mucho la atención en India. Los temas de los refugiados se limitan a los asilados y los solicitantes de asilo en India, más que de los provenientes de dicha nación.
} 
análisis de la dimensión de género en la migración india se basan todavía en estereotipos o en estudios de caso. ${ }^{23}$

Es claro que se ha mostrado cierta preocupación seguida de acciones diplomáticas en cuanto a la suerte de los trabajadores migrantes de origen hindú empleados en el extranjero, sobre todo cada vez que surge una crisis, ya sea la guerra del Golfo, la Guerra de Irak o los secuestros aleatorios de conductores de camión de origen hindú, la reciente decapitación de un ingeniero hindú por terroristas en Afganistán o los súbitos arrestos de profesionales hindúes de la Ti en Malasia y Holanda, entre otros acontecimientos (Hindustan Times, Times of India, Straight Times, abril-mayo de 2006). Sin embargo, India prácticamente no ejerce control alguno de los flujos migratorios de las categorías de personal altamente calificado. Incluso, los flujos de trabajadores no calificados son controlados apenas en lo que compete al área de aplicación de los permisos para emigrar a las categorías de pasaporte correspondientes (Emigration Clearance Required-ECR), con las limitaciones ya mencionadas. En consecuencia, aún no se ha contemplado la posibilidad de que la propia migración haya generado una sensación de desesperación entre el pueblo hindú de bajos ingresos, con intención de emigrar para lograr cierta movilidad socioeconómica ascendente para la familia que deja en India, incluso asumiendo los riesgos que acompañan a la migración al extranjero. De manera paralela, no existen estudios del impacto de la migración calificada en las decisiones profesionales y las opciones de educación en India, en donde se ha distorsionado en mucho el proceso de decisión y se han generado conflictos intergeneracionales e incluso entre comunidades, por las decisiones educativas que se han dado pero que siguen fuera del análisis y de la conciencia del público ${ }^{24}$ (Khadria, 2004b; NCAER, 2005).

A nivel macro, los intentos no han progresado más allá de la identificación de los indicadores como las remesas, la transferencia de tecnología y el capital humano encarnado en los migrantes de retorno (Khadria, 1999, 2002). Aún en el caso de la evaluación macroeconómica de las muy mencionadas remesas, se ha dado un «flujo silencioso de retorno» desde los países de origen en el sur, como India, hacia los países de destino en el norte como Reino Unido, Australia y Estados Unidos, a guisa de cuotas escolares «de estudiantes en el extranjero» (Khadria, 2004c, 2006a). Este monto no se ha calculado todavía y mucho menos se ha analizado. Los aumentos en el ingreso adicional de los hogares de Kerala, que surge de las remesas, han tenido sus efectos en el patrón de consumo en el estado, incluida la inversión familiar en educación orientada a la migración (Zachariah y Rajan, 2004) ${ }^{25}$. Pero las actividades de consumo y construcción de vivienda han privado al

\footnotetext{
${ }^{23}$ Por ejemplo, una de esas dimensiones olvidadas del género, en la emigración altamente calificada, ha sido la negativa a admitir que trabajen los cónyuges-dependientes que tienen visas $\mathrm{H}-4$, principalmente mujeres que acompañen a los migrantes hindúes varones con las famosas visas $\mathrm{H}-1 \mathrm{~B}$ en Estados Unidos, lo que hace que se genere una dependencia en lo financiero y en la movilidad respecto a los esposos, seguida de discriminación, explotación y, a veces, maltrato. Véase Devi (2002) citado en Van der Veer (2005: 283).

${ }^{24}$ Viene al caso la reciente agitación en India por la reserva de lugares, en las instituciones de educación superior, para las castas desprotegidas.

${ }^{25} \mathrm{Al}$ mismo tiempo, las remesas han favorecido, por un lado, que se abra una gran cantidad de nuevas escuelas e instituciones de educación superior y ha permitido, a los jóvenes, acceder a la costosa educación privada por el
} 
estado del desarrollo potencial de su recepción de remesas, haciendo que muchas familias caigan en la bancarrota financiera e incluso en suicidios. Además, la creciente influencia económica y política de los «nuevos ricos» en Kerala, se reporta, ha generado un clima de resentimiento en contra de ellos por otras comunidades (Zachariah y Rajan, 2004).

A pesar de todo, mientras que el volumen de las remesas enviadas por los trabajadores migrantes hindúes en el Golfo han llamado mucho la atención, las otras dos áreas, es decir, la transferencia de tecnología y la migración de retorno, que se concebían como la consecuencia positiva de la migración calificada a los países desarrollados, no han sido evaluadas adecuadamente, ni siquiera en términos cuantitativos. La mayor parte de los estudios no han ido más allá de hablar acerca de la necesidad de evaluar los resultados cuantitativos en términos de los volúmenes de flujos de colaboración tecnológica y las cantidades de retornados. La recolección y disponibilidad de los datos han sido las principales limitaciones para los investigadores que tratan de ir más lejos en estas dos áreas. Aun cuando la información esporádica sobre la transferencia de tecnología ha revelado una imagen no necesariamente halagüeña de las contribuciones en el campo de la transferencia de tecnología; en cambio, la «transferencia inversa de tecnología», término utilizado por estudios de la UNCTAD realizados en los años setenta, desde los países del sur hacia el norte, todavía parece continuar en la forma de fuga de cerebros, sobre todo en el área de TI (Khadria, 1990). La migración de retorno se ha convertido en un tema central en el contexto de los sistemas de outsourcing de los procesos empresariales hacia India, después de que la burbuja de las ti se reventara en Estados Unidos, pero aún en este caso, hace falta una evaluación sistemática de las cantidades y cualidades de las personas que retornan, los pocos estudios sobre el tema hacen énfasis en que el retorno a India es insostenible porque quienes regresan tienden a irse nuevamente, tras una breve estancia en India (Saxenian, 2005). Por supuesto que se ha observado cierto patrón de retornos circulares entre las actividades de las ONG's relacionadas con el desarrollo socioeconómico a nivel de las bases, pero hasta el momento se trata de información sumamente anecdótica (Khadria, 2002).

Algo que sería útil, como herramienta de política, es el «análisis adversario» (adversary analysis) por el cual se evalúa la contribución al desarrollo social y económico de los países de origen desde el punto de vista de quienes actúan en los países de destino. Para hacerlo en un marco de relaciones multilaterales internacionales, como en los foros de la Organización Mundial de Comercio (омc), los beneficios de las remesas, de la tecnología y de la migración de retorno hacia los países de origen en el sur puede medirse e incluso compararse con las tres ventajas de «la edad, el sueldo y la cosecha»

otro, ambas cosas han favorecido que crezca el desempleo entre las actuales generaciones de jóvenes en Kerala, quienes ya no quieren trabajar en las líneas de ocupación tradicionales. En segundo lugar, un efecto «adverso», igualmente importante, ha sido el surgimiento de la «migración de reemplazo» por parte de mano de obra que llega a Kerala proveniente de otros estados de India. Además del hecho de que los salarios han subido en Kerala hasta convertirse en los más altos de India, debido a la escasez de trabajadores no calificados y semicalificados, los trabajadores manuales provenientes de otros estados también aceptan bajos sueldos y pobres condiciones de vida, con tal de trabajar en Kerala, aumentando el desempleo de las generaciones locales de jóvenes. 
(Age, Wage, and Vintage) que corresponden a los países de destino en el norte. Tales son las ventajas que se derivan de una mayor rotación de migrantes que se incluye en la migración temporal y circular y que puede operacionalizarse como: a) atraer la llegada de migrantes más jóvenes para equilibrar la población que comienza a envejecer; b) conservar bajos los compromisos de sueldos y pensiones al reemplazar a los migrantes de mayor edad y de largo plazo con migrantes más jóvenes con estancias más cortas, y c) acumular la reserva de conocimiento cosechada más recientemente que se encarna, respectivamente, en las jóvenes generaciones de trabajadores calificados (Khadria, 2006a: 194). Todavía está por verse y explorarse cuáles son los aspectos de costos asociados con los beneficios.

Los cambios en las percepciones de los países de destino, en los que se han establecido los migrantes hindúes con grados profesionales para formar una diáspora, podrían desempeñar un papel de catalizadores. Los valores que han cambiado se atribuyen ahora a la propia diáspora india, que ha sido capaz de desafiar el anticipado fracaso, al elevarse hasta lograr un éxito económico no previsto en los países de destino en el norte, lo que ha desembocado en un cambio de paradigma en las sociedades y regiones en donde se han establecido los hindúes. ${ }^{26}$ La explicación parece estar en que, en los países de destino, se ha suscitado la conciencia de que, dado el tipo adecuado de apoyo, los recursos y la ayuda local, un tipo de migrantes - que era sospechoso de ser un «parásito social»—- puede convertirse en el otro lado de la moneda, el exitoso social o, como lo ha expresado alguien, jla «gran esperanza blanca de librarse de los blancos» de occidente (great off-white hope)! (Alibinia, 2000).

Lo anterior ha significado un importante cambio de paradigma también en India: ver la migración como un proceso que ha llevado a la formación de «la diáspora hindú», una posibilidad de responder al desafío de la migración convirtiéndolo en una oportunidad y, por tanto, con posibilidades de ganancia. ${ }^{27}$ Lo que le queda a India, así como a estos países receptores en el emergente paradigma de relaciones internacionales, es juzgar, ¿en dónde quedará la lealtad de la diáspora india? Y, además, ¿los migrantes hindúes ya no serán tratados por India como los «desertores de la madre patria» y como «parásitos sociales» por los países de destino?

La opción de la diáspora, debido a su identidad holista, también podría impulsar un punto que se ha dado en el informe de GCIM (2005), al señalar que

[...] la distinción tradicional entre trabajadores calificados y no calificados en ciertos aspectos no es útil pues no hace justicia a la complejidad de la migración internacional [...] Aun cuando pueden tener diferentes niveles de logro educativo, todos podrían ser descritos legítimamente como trabajadores esenciales (énfasis añadido).

\footnotetext{
${ }^{26}$ En la actualidad, Gran Bretaña es un interminable repositorio de historias de éxito de la diáspora de profesionales hindúes, que va desde Lord Swraj Paul, hasta el magnate del acero Laxmi Mittal, e iconos como el premio Nóbel Amartya Sen.

${ }^{27}$ Véase Barré et al., eds. (2003) sobre la diáspora como una opción de política.
} 
Aunque la dicotomía entre trabajadores migrantes calificados y no calificados no tenga bases, en los últimos tiempos, India ha atraído una atención desproporcionada en todo el mundo por sus historias de éxito, en las que los recursos humanos altamente calificados se han desempeñado notablemente bien en el mercado laboral extranjero - los profesionales de la Ti, las enfermeras, los tecnólogos, los administradores de finanzas, los científicos, los arquitectos, los abogados, los maestros y otros más- haciendo que, en los países desarrollados, casi se den disputas por ellos, al lograr que la tarjeta verde alemana, la visa $\mathrm{H} 1-\mathrm{B}$ de Estados Unidos, el permiso británico de trabajo, la visa de inversión canadiense, la visa australiana de estudiante, la ciudadanía de Nueva Zelanda, aparezcan para hacerse del talento indio encarnado en los trabajadores y en los estudiantes. En contraste, los trabajadores migrantes hindúes en el Golfo han sido considerados más una responsabilidad que un orgullo para India. Para neutralizar este desequilibrio y dotar de poder a los trabajadores migrantes hindúes, se contempla cada vez más a los involucrados en el Golfo (y también en el sur y el sureste de Asia) a la vez que se promueven programas innovadores. Los desarrollos que siguieron a la institución del «Pravasi Bhartiya Divas» (día de los expatriados hindúes) y a la constitución de un ministerio especializado en el gobierno de India reflejan una ruptura con el pasado, una confianza que emana de un cambio de paradigma orientado hacia el propósito de que India se enorgullezca de su diáspora y viceversa.

Lo que se requiere, sin embargo, es una política a largo plazo dirigida a establecer vínculos entre India y la diáspora hindú, para impulsar el desarrollo socioeconómico sostenible en el país. Pero para lograr una proverbial situación de «gana-gana» en las relaciones internacionales para los tres involucrados - India como país de origen ubicado en el sur, los migrantes hindúes como parte de su diáspora y los países de destino en el norte-, deben cumplirse dos condiciones específicas: una «condición necesaria» de la presencia global geoeconómica dominante o significativa de los trabajadores hindúes, y una «condición suficiente» por medio de la cual India derive beneficios sostenibles de esa presencia geoeconómica global. En términos de la gran demanda de trabajadores hindúes en el extranjero, tanto los calificados como los no calificados, y de los migrantes al establecer excelentes marcas de desempeño en los mercados laborales de los países de destino, la primera condición se ha cumplido relativamente. Para satisfacer la condición suficiente en la que India derive ganancias significativas de la presencia geoeconómica global de los migrantes hindúes, los flujos de remesas, la transferencia de tecnología y la migración de retorno han de dirigirse, todas, no «desde arriba hacia abajo» sino «desde abajo hacia arriba», no orientadas hacia el comercio y los negocios sino hacia la remoción de dos tipos de pobreza en India: «pobreza en educación» y «pobreza en salud», áreas en donde la migración, hasta el momento, no ha logrado cambiar a la sociedad de origen contribuyendo a su desarrollo económico y social. Las grandes masas de población, analfabetas y de escasa educación, incapacitadas aún más por su precaria situación de salud, constituyen las causas profundas de que India posea uno de los promedios más bajos en productividad de su fuerza de trabajo y, por lo tanto, los más bajos salarios en el mundo, una paradoja cuando los miembros de la diáspora india, en promedio, figuran entre las comunidades étnicas que más contribuyen en sus 
países de destino. Por ejemplo, la contribución promedio por hora de cada trabajador con empleo dentro de India, al PIB, ha estado entre los más bajos del mundo, apenas 37 centavos que se compara desfavorablemente con los 37 dólares de Estados Unidos, es decir, una centésima de este último. Naturalmente que esto es irónico porque el mismo hindú promedio, empleado en el extranjero, contribuye con una muy alta porción al PIB del país en el que se establece y trabaja (Khadria, 2002). Las redes y asociaciones de la diáspora hindú en el extranjero podrían, por ende, desempeñar un papel de catalizadoras - ya sea en lo económico, político o cultural - para elevar la productividad de la masa de trabajadores hindúes en su país al concebir áreas como la salud y la educación para promover, posiblemente, la participación de la diáspora, en vez de enfocarse en empresas de «ganancia» inmediata en la industria y el comercio.

Ello establece un «doble desafío» en la política pública para un país de origen como India: primero, convencer a su propia diáspora para que replantee el proceso de desarrollo en India como una creación «desde abajo», así como que proporcione apoyo para promover la productividad sostenible de la mano de obra por medio del desarrollo de la educación y la salud. Esto cambiará el sentido de lo hecho hasta ahora, de plantear un desarrollo «desde arriba» al promoverse la participación de la diáspora en el comercio y la industria - una integral, la otra dispersa; una a largo plazo, la otra inmediata-. No es sólo asunto de voluntad; en muchos casos, ello llevará largos periodos de lucha para generar capacidades para la toma de decisiones y el establecimiento de prioridades entre los líderes de la comunidad de migrantes. En segundo lugar, India debe de ser capaz de convencer a los países de destino (y también a los otros países de origen en el sur) para que distingan entre los impactos socioeconómicos más «dolorosos» y los más «rentables» de la migración de sus trabajadores, tanto los calificados como los no calificados. El «análisis adversario», en foros multilaterales, ayudará a que un país como India haga presión para impulsar por normas internacionales en las negociaciones de la OMC en torno al tema del movimiento natural de personas como proveedores de servicios, lo que constituye, simplemente, otra descripción para promover el ingreso temporal de los migrantes. En los diálogos multilaterales, la vulnerabilidad de los migrantes y la inestabilidad de las tendencias que subyacen a la «política de abrir y cerrar» de los países de destino en el norte podrían ser los dos aspectos claves que los países de origen en el sur habrían de negociar, al considerarlos como los más dañinos de la migración internacional.

\section{BIBLIOGRAFÍA}

Abella, M. (2006), «Global Competition for Skilled Workers and Consequences», en Kuptsch, C. y Pang, E. F. (eds.), Competing for Global Talent, International Institute for Labour Studies, ILO, Ginebra, pp. 11-32.

alibinia, A. (2000), «The Great Off-White Hope», The Hindustan Times, Nueva Delhi, 26 Sept.

BAKER, R. S. (1937), Woodrow Wilson-Life and Letters: Facing war, 1915 -1917, vol. 6, Doubleday, Doran \& Co, Garden City, Nueva York,. 
BARRÉ, R., V. Hernandez, J-B. Meyer y D. Vinck (eds.) (2003), Scientific Diasporas, IRD, París.

Bhagwati, J. N. (1982), «Directly Productive Unproductive Profit-seeking (DUP) Activities», Journal of Political Economy, 90, 5, pp. 988-1002.

BIRKs, J. S. y Sinclair, C. A. (1980), International Migration and Development in the Arab Region, International Labour Office, Ginebra.

Blaug, M., Layard, P. R. G. y Woodhall, M., The Causes of Graduate Unemployment in India, Penguin, Londres.

Bose, A., 1983, «Migration in India: Trends and Policies», en A. S. Oberai (ed.) (1983), State Policies and Internal Migration: Studies in Market and Planned Economies, Croom Helm, Londres, pp.137-182.

CHIswick, B. R. (1978), «The Effects of Americanization on the Earnings of Foreignborn Men», Journal of Political Economy, 86, pp. 897-921.

DEVI, S. U. (2002), «Globalisation, Information technology and Asian Indian Women in the US», Economic and Political Weekly, Octubre.

DREZE, J. y Sen, Amartya (1996), India: Economic Development and Social Opportunity, Oxford University Press, Delhi.

Drucker, P. (1993), Post-Capitalist Society, Harper Collins, Nueva York.

ECEvit, Z. H. (1981), «International Labour Migration in the Middle East and North Africa: Trends and Policies», en M. M. Kritz, C. B. Keely y S. M. Tomasi (eds.) (1981), Global Trends in Migration: Theory and Research on International Population Movements, Center for Migration Studies, Nueva York, pp. 259-275.

economic times, The, Edición de Nueva Delhi, varios números, según se citan en el texto.

ELAHI, K. M. y Sultana, S. (1985), «Population Redistribution and Settlement Change in South Asia: A Historical Evaluation», en L. A. Kosinski y K. M. Elahi (eds.), Population Redistribution and Development in South Asia, D. Reidel Publishing, Dordrecht, pp. 15-35.

GCIM (2005), «Migration in an Interconnected World: New Directions for Action», Report of the Global Commission on International Migration, Ginebra.

GoI, Census 1991, Registrar General of India, Government of India, Nueva Delhi.

GoI, Census 2001, Registrar General of India, Government of India, Nueva Delhi.

GOI, MOIA, Annual Report 2004-05, Ministry of Overseas Indian Affairs, Government of India, Nueva Delhi.

GOI, MOIA, Annual Report 2005-06, Ministry of Overseas Indian Affairs, Government of India, Nueva Delhi.

GOI, MOIA (2006), Proceedings of the Conference of the Indian Ambassadors of Gulf Countries, at Doha, Qatar, March 20-21, Ministry of Overseas Indian Affairs, Government of India, Nueva Delhi, texto inédito.

HARwood, E. (1986), «American Public Policy and U.s. Immigration Policy», The Annals of the American Academy of Political and Social Sciences, vol. 487, Special issue on Immigration and American Public Policy, September, pp. 201-212.

HINDU, The, Edición de Nueva Delhi, según se cita en el texto. 
hindustan Times, The, Edición de Nueva Delhi, varios números, según se cita en el texto.

ICWA, 2001, Report of the High Level Committee on the Indian Diaspora, Indian Council of World Affairs, Nueva Delhi.

INDiRESAN, P. V. y Nigam, N. C. (1993), «Indian Institutes of technology: Excellence in peril», en S. Chitnis y P. G. Altbach (eds.) (1993), Higher Education Reforms in India-Experience and Perspectives, Sage, Nueva Delhi.

INSTITUTE OF INTERNATIONAL EDUCATION (2004), Open Doors 2004: Report of International Educational Exchange, Washington D.C.

INSTITUTE OF INTERNATIONAL EDUCATION (2005), Open Doors 2005: Report of International Educational Exchange, Washington D.c.

IOM (2004), Return Migration: Policies and Practices in Europe, IOM International Organization for Migration, Ginebra.

JENSEn, J. M. (1988), Passage from India-Asian Indian Immigration in North America, Yale University Press, Nueva Haven.

Keely, C. B. (1980), Asian Worker Migration to the Middle East, Working Paper, Population Council, Center for Policy Studies, Nueva York.

Kelegana, S. y Parikh, K. S. (2003), «Political Economy of Growth and Reforms in South Asia», en I. S. Ahluwalia y J. Williamson (eds.) (2003), The South Asian Experience with Growth, Oxford University Press, Nueva Delhi, pp. 80-145.

KHADRIA, B. (1990), «Patents, Brain Drain and Higher Education: International Barriers to the Diffusion of Knowledge, Information and Technology», Social Scientist, Serial No. 204, vol. 18, no. 5, mayo, pp. 3-18, Nueva Delhi.

KHADRIA, B. (1999), The Migration of Knowledge Workers: Second-Generation Effects of India's Brain Drain, Sage Publications, Nueva Delhi.

KHAdRIA, B. (2001a), «Shifting Paradigm of Globalization: The Twenty-first Century Transition towards Generics in Skilled Migration from India», International Migration, Special Issue: International Migration of the Highly Skilled, vol. 39, No. 5, pp. $45-71$.

KHADRIA, B. (2001b), Report of a Sample Survey in JNU and IITD for Estimating the Social Cost of Civil Services Examination, mimeo., Union Public Service Commission, Government of India, Nueva Delhi.

KHADRIA, B. (2002), «Skilled Labour Migration from Developing Countries: Study on India», International Migration Papers 49, International Labour Office, Ginebra. KHADriA, B. (2003), «Case Study of the Indian Scientific Diaspora», en Barré et al (eds.), Scientific Diasporas: How Can Developing Countries Benefit from Their Expatriate Scientists and Engineers?, Institut de Reserche pour le Developpment (IRD), París.

KHADRIA, B. (2004a), «Migration of Highly Skilled Indians: Case Studies of IT and Health Professionals», stı Working Paper 2004/6, oECD, París.

KHADRIA, B. (2004b), «Human Resources in Science and Technology in India and the International Mobility of Highly Skilled Indians», STI Working Paper 2004/7, Mayo, OECD, París.

KHADRIA, B. (2004c), «Skilled Labour Migration from India», en H. Oda (ed.), Interna- 
tional Labor Migration from South Asia, ASEDP 70, Institute of Developing Economies (IDE) - Japan External Trade Organization (JETRO), (ISBN4-258-55070-1 C3033), pp. 7-55.

KHADRIA, B. (2006a), «Embodied and Disembodied Transfers of Knowledge: Geo-politics of Economic Development», en M. Carton y J.-B. Meyer (eds.), Knowledge for Development, l'Harmattan, París, pp. 191-203.

KHADRIA, B. (2006b), International Competition for ser Students and Workers: An Evaluation of Trends and Policies in India and Southeast Asia, Paper Presented the Conference on Global Competition for International Students, organised by Institute for the Study Of International Migration (ISIM), Georgetown University, Washington D.C., 31 de marzo, 2006.

KHADRIA, B., (2006c), Entry on «Post-war migration», Chapter on «The Age of Globalisation», en B. V. Lal (General Editor), The Encyclopedia of the Indian Diaspora, Editions Dodier Millet, Singapur.

KHADRIA, B. (en prensa), «Tracing the Genesis of Brain Drain in India through its State Policy and Civil Society», en N. Green y F. Weil (eds.), Citizenship and Those Who Leave: The Politics of Emigration and Expatriation, University of Illinois Press (En prensa, 2007).

KHADRIA, B. y Leclerc, E. (2006), «Exode des emplois contre exode des cerveaux, les dau faces d'une meme piece?», Autrepart: Revue des sciences sociales au sud, No. 37, Special issue on La Migration des Emplois Vers le Sud, IRD Editions, France.

kosinski, L. A. y Elahi, K. M. (eds.) (1985), Population Redistribution and Development in South Asia, D. Reidel Publishing, Dordrecht.

Kosinski, L. A. y Elahi, K. M. (1985), «Introduction», en L. A. Kosinski y K. M. Elahi (eds.), Population Redistribution and Development in South Asia, op. cit., pp. 3-14.

Krishna, V. V. y Khadria, B. (1997), «Phasing Scientific Migration in the Context of Brain Gain and Brain Drain in India», Science, Technology \& Society, 2, 2, JulioDic., pp. 347-386.

krueger, A. O. (1974), «The Political Economy of Rent-seeking Society», American Economic Review, 64, 3, 99, pp. 291-303.

MARTin, P. y Widgren, J. (1996), «International Migration: A Global Challenge», Population Bulletin, vol. 51, núm.1, Abril.

majumdar, T. (1994), «Old World is the New World», The Telegraph, 8 de Agosto, Calcuta.

MOORE, S. (1986), «Social Scientist's Views on Immigrants and U.s. Immigration Policy», The Annals of the American Academy of Political and Social Sciences, vol. 487, Special issue on Immigration and American Public Policy, Septiembre, pp. 213-217.

NASSCOM (2002), Strategic Review 2002, Chapter 5: «Knowledge Professionals», National Association of Software and Service Companies, Nueva Delhi, pp. 63-82.

NAsscom (2005a), The IT Industry in India: Strategic Review 2005, National Association of Software and Service Companies, Nueva Delhi. 
NASSCOM (2005b), Extending India's Leadership of the Global IT and BPO Industries,

Nasscom-McKinsey Report 2005, National Association of Software and Service Companies, Nueva Delhi.

NCAER (2005), India Science Report, National Council of Applied Economic Research, Nueva Delhi

OECD, 2004, Trends in International Migration: Annual Report 2003 Edition, Organisation for Economic Cooperation and Development, París.

OVERSEAS INDIAN (2006), vol. 1, Nos. 1-4, January-April, Monthly publication of the Ministry of Overseas Indian Affairs, Government of India, Nueva Delhi PREMI, M. (1990), «India», en C. B. Nam, W. J. Serow y D. F. Sly (eds.) (1990), International Handbook on Internal Migration, Greenwood Press, Nueva York, pp. 189-206.

RAHMAN, A. (1999), «Indian Labour Migration to West Asia: trends and effects», Manpower Journal, 35, 2, Julio-Sept.

RAJAN, I.S. (2003), «Dynamics of International Migration from India: Its Economic and Social Implications», paper presented at the Ad Hoc Expert Group Meeting on Migration and Development, 27-29 August, United Nations Economic and Social Commission for Asia and the Pacific, Bangkok,.

RAJAN, S. I. (2004), «From Kerala to the Gulf: Impacts of Labour Migration», Asian and Pacific Migration Journal, 13, 4.

SaXenian, AnnaLee (2005), «From Brain Drain to Brain Circulation: Transnational Communities and Regional Upgradation in India and China», Studies in Comparative International Development, Otoño.

SEN, Amartya (1973), «Brain Drain: Causes and Effects», en B. R. Williams (ed.) (1973),

Science and technology in Economic Growth, Macmillan, Edimburgo.

SKeldon, R. (1985), «Migration in South Asia», en L. A. Kosinski y K. M. Elahi (eds.),

Population Redistribution and Development in South Asia, op. cit., pp. 37-64. STRAit times, The, Singapur, según se cita.

teitelbaum, M. S. y Weiner, M. (eds.) (1995), Threatened Peoples, Threatened Borders: World Migration and U.s. Policy, w. w. Norton and Co., for the American Assembly, Columbia University, Nueva York.

TINKER, Hugh (1974), A New System of Slavery: Export of Indian Labour Overseas, 1830-1920, Oxford University Press, Oxford.

TINker, Hugh (1976), Separate and Unequal: India and Indians in the British Commonwealth, 1920-1950, Vikas, Nueva Delhi.

Tinker, Hugh (1977), The Banyan tree: Overseas Emigrants from India, Pakistan and Bangladesh, Oxford University Press, Oxford.

united nations (1982), Population Policy Briefs: Current Situation in Developing Countries and Selected Territories, United Nations (ESA/P/w.P67/REv.1), Nueva York. U.s. National Science Foundation, Science and Engineering Indicators 2000.

U.s. Census Bureau (2004), «We the People-Asians in the United States», Census 2000 Special Reports CENSR-17, Diciembre, Department of Commerce.

U.s. DHS, Statistical Yearbook, diversos años, Department of Homeland Security, Washington D.C. 
U.s. INS, Statistical Yearbook, various years, Immigration and Naturalization Service,

Department of Justice, Washington D.C.

VAN DER Veer, P. (2005), «Virtual India: Indian it Labor and the Nation-State», en T.

B. Hansen y F. Stepputat (eds.) (2006), Sovereign Bodies: Citizens, Migrants, and States in the Postcolonial World, Princeton University Press, Princeton.

WEINER, M. (1978), Sons of the Soil: Migration and Ethic Conflict in India, Oxford University Press, Bombay.

WeIner, M. (1982), «International Migration and Development: Indians in Persian Gulf», Population and Development Review, 8, 1, pp. 1-36.

WORLD BANK (2005), World Economic Outlook, Washington D.C.

wORld focus (2001), Special Issue on Indian Diaspora-Its Positive Contribution, No. 255, Marzo.

Zachariah, K. C. y Rajan, S. I. (2004), «Gulf Revisited», Working Paper Series 363, Centre for Development Studies, Thiruvananthapuram.

Zachariah, K. C., Mathew, E. T. y Rajan, S. I. (2000), «Social, Economic and Demographic Consequences of Migration in Kerala», Working Paper Series 303, Centre for Development Studies, Thiruvananthapuram.

ZaChariah, K. C., Mathew, E. T. y Rajan, S. I. (2003), Dynamics of Migration in Kerala: Dimensions, Differentials and Consequences, Orient Longman, Nueva Delhi.

ZaChariah, K. C., Prakash, B. A. y Rajan, I. S. (2002), «Working in the Gulf: Employment, Wages and Working Conditions», en K. C. Zachariah, K. P. Kannan e I. S. Rajan (2002), Kerala's Gulf Connection, Centre for Development Studies, Thiruvananthapuram, pp. 129-97. 